\title{
Numerical simulation of hydraulic fracturing in enhanced geothermal systems considering thermal stress cracks
}

\section{Ziyang Zhou ( $\square$ zhouzytju@outlook.com )}

Department of Civil and Earth Resources Engineering, Kyoto University https://orcid.org/0000-00031297-4948

\section{Hitoshi MIKADA}

Department of Civil and Earth Resources Engineering, Kyoto University

\section{Junichi TAKEKAWA}

Department of Civil and Earth Resources Engineering, Kyoto University

\section{Shibo Xu}

Department of Civil and Earth Resources Engineering, Kyoto University

\section{Research Article}

Keywords: Enhanced geothermal systems, Distinct element method, Hydraulic fracturing, Thermal stress crack

Posted Date: June 8th, 2021

DOI: https://doi.org/10.21203/rs.3.rs-597546/v1

License: (c) (1) This work is licensed under a Creative Commons Attribution 4.0 International License. Read Full License

Version of Record: A version of this preprint was published at Pure and Applied Geophysics on March 16th, 2022. See the published version at https://doi.org/10.1007/s00024-022-02996-z. 
Numerical simulation of hydraulic fracturing in enhanced geothermal systems considering thermal stress cracks

\section{Authors:}

\section{Ziyang Zhou ${ }^{1}$}

${ }^{1}$ Department of Civil and Earth Resources Engineering, Kyoto University

e-mail: zhouzytju@outlook.com

\section{Hitoshi MIKADA ${ }^{1}$}

${ }^{1}$ Department of Civil and Earth Resources Engineering, Kyoto University e-mail: mikada@gakushikai.jp

\section{Junichi TAKEKAWA ${ }^{1}$}

${ }^{1}$ Department of Civil and Earth Resources Engineering, Kyoto University

e-mail: takekawa@tansa.kumst.kyoto-u.ac.jp

\section{Shibo $\mathrm{Xu}^{1}$}

${ }^{1}$ Department of Civil and Earth Resources Engineering, Kyoto University

e-mail: shibo.xu@tansa.kumst.kyoto-u.ac.jp

\section{Corresponding author:}

\section{Ziyang Zhou}

Department of Civil and Earth Resources Engineering, Kyoto University

e-mail: zhouzytju@outlook.com

Phone: $+81-50-6865-2951$

Postal address: C1-1-119, Kyotodaigaku-Katsura, Nishikyo-ku, Kyoto, Japan

\section{Final version}

Date: 6. 4. 2021 


\begin{abstract}
With the increasing attention to clean and economical energy resources, geothermal energy and enhanced geothermal systems (EGS) have gained much importance. For the efficient development of deep geothermal reservoirs, it is crucial to understand the mechanical behavior of reservoir rock and its interaction with injected fluid under high temperature and high confining pressure environments. In the present study, we develop a novel numerical scheme based on the distinct element method (DEM) to simulate the failure behavior of rock by considering the influence of thermal stress cracks and high confining pressure for EGS. We validated the proposing method by comparing our numerical results with experimental laboratory results of uniaxial compression tests under various temperatures and biaxial compression tests under different confining pressure regarding failure patterns and stress-strain curves. We then apply the developed scheme to the hydraulic fracturing simulations under various temperatures, confining pressure, and injection fluid conditions. Our numerical results indicate that the number of hydraulic cracks is proportional to the temperature. At a high temperature and low confining pressure environment, a complex crack network with large crack width can be observed, whereas the generation of the micro cracks is suppressed in high confining pressure conditions. In addition, high-viscosity injection fluid tends to induce more hydraulic fractures. Since the fracture network in the geothermal reservoir is an essential factor for the efficient production of geothermal energy, the combination of the above factors should be considered in hydraulic fracturing treatment in EGS.
\end{abstract}

Keywords: Enhanced geothermal systems, Distinct element method, Hydraulic fracturing, Thermal stress crack. 


\section{Introduction}

The utilization of renewable energy increased by $13.7 \%$ (British Petroleum, 2020) in 2019. In particular, the proportion of geothermal energy consumption has continued to rise in many countries in recent years (International Energy Agency, 2020) because of its characteristics such as geographical distribution, base-load dispatchability without separate energy storage, and other advantages (Tester et al., 2006). Since there are some limitations in the conventional geothermal energy extraction to exploit the subsurface hydrothermal circulation (Lund et al., 2008, for example), the enhanced geothermal system (abbreviated as EGS, hereafter) was proposed so that heat could be extracted from artificially created reservoirs (Potter et al., 1974). In EGS, injection wells are drilled into the thermal storage rock formation, through which fluid will be injected to create cracks in the rock formation artificially. After this treatment, a significant number of cracks will be generated in the thermal storage rock formation, forming a complex fracture network through which the geothermal energy contained in the surrounding rocks will be transmitted to power stations on the ground surface. Unlike conventional geothermal power generation methods, the heat storage rock formations used for EGS do not have to contain fluid or steam to use more geothermal resources (Pruess, 2006; Olasolo et al., 2016). EGS, therefore, opened a new path for geothermal development in an environment with poor hydrothermal circulation and for recovering the enormous amount of thermal energy stored in the earth beyond the conventional geothermal resources (Tester et al., 2006). For efficient heat production in EGS, it is crucial to create a long and complicated fracture network in the reservoir rock. At present, the most commonly used technology is hydraulic fracturing (Lu et al., 2018), which induces fractures by injecting fluid into the rock formation. The fractures will propagate, coalesce, and eventually form a complex fracture network with the continuous injection of liquid (Montgomery and Michael, 2010). Although hydraulic fracturing is not always successful in past experiments, technological development for artificial reservoir generation and physical property estimation through hydraulic fracturing are vital areas of interest (Tester et al., 2006). Since geothermal power research aims to obtain even higher thermal energy, the depth of interest moves toward the region thought to be below the brittle-ductile transition zone in the ground (Reinsch et al., 2017). The investigation of rocks' physical and mechanical properties around these regions, which change as functions of temperature and pressure, has to be made to better deal with corresponding hydraulic fracturing (Zhang et al., 2018).

Many factors are influencing the behavior of hydraulic fracturing in EGS, including state quantities such as confining pressure and temperature, mechanical properties of rock and injected fluid, and the coupling effect of these parameters. Due to the limitations in the conditions of experimental studies, many researchers have studied the influence of a single factor on conventional rock specimens: the effects of high-temperature treatments of granite samples (Yang et al., 2017), the impact of thermal deterioration on the physical and mechanical properties 
of rocks after multiple cooling shocks (Shen et al., 2020), or an intragranular damage mechanism in the brittleductile transition in porous sandstone (Wang et al., 2008), for example. Although these studies have made elucidating discussion on the brittle-ductile transition under high confining pressure or the effect of hightemperature treatment, their results could provide no direct indication for the hydraulic fracturing process in EGS. It is presumed that the zones suitable for EGS located at a depth of 3 to 10 kilometers underground (Lu and Wang, 2015) have the low-permeability and high temperature, and the results of hydraulic fracturing in such an environment need to be well estimated before any practice. Although the laboratory experiments on hydraulic fracturing in the conditions near brittle-ductile transition were carried out (Watanabe et al., 2017), their experiments were restricted to the laboratory scale due to severe conditions both in pressure and in temperature of the brittle-ductile transition zones. Numerical experiments realizing such severe conditions have high value for studying the behavior of hydraulically created fractures and supercritical waters beyond the laboratory scale. It is indispensable to clarify the influence of the above state quantities and mechanical properties qualitatively in the practice of EGS near brittle-ductile transition zones.

In this study, we employed an approach of the distinct element method (DEM; Cundall and Strack, 1979) for our numerical simulation because of its high applicability to reproduce intermittent behavior of rock failure and hydraulic fracturing (Tarasovs and Ghassemi, 2012; Tomac and Gutierrez, 2017; Nagaso et al., 2019; Ohtani et al., 2019a, 2019b, 2019c, for example). In our approach, we tried to supplement the deficiencies in the current studies by introducing the following attempts. We considered the thermal volumetric changes of rock grains due to high temperature that could cause fracturing. The effects of initial thermal stress cracks on the mechanical response of reservoir rock formation in hydraulic fracturing are included in our numerical simulation. Moreover, we avoided the two-step procedure, i.e., heating and cooling, to study the thermal response of rock specimens in the laboratory test, to conduct our numerical experiments in environments much closer to the actual practice of EGS. Our numerical experiments would well simulate hydraulic fracturing in EGS under high confining pressure and high-temperature conditions. We propose a solid-liquid-thermal coupling model to study the mechanical behavior of rock under such conditions using DEM. This paper will qualitatively study the influence of different factors through multiple sets of numerical experiments after validating the developed scheme by comparing laboratory results of the uniaxial and biaxial compression tests. Based on the hydraulic fracturing simulations with several combinations of temperature, confining pressure, and injection fluid, we try to find the role of environmental temperature and pressure and the viscosity of injection fluid in a complex fracture network generation.

\section{Methodology}


In this section, we explain the details of DEM and our original strategy for reproducing the mechanical behavior of rock and injected fluid and their interaction. At first, the conventional DEM theory is briefly reviewed. Then, our proposed scheme for incorporating the effects of temperature, confining pressure, and hydro-thermalmechanical interactions into DEM is introduced.

\subsection{The basic theory of distinct element method and bonded particles model}

The strength of the rock material as a whole can be achieved by introducing a bond between grains in DEM (Potyondy and Cundall, 2004). In a two-dimensional case, the intact rock is modeled as a dense packing of small rigid circular grains. Neighboring grains are bonded together at their contact points with normal, shear, and rotational springs and interact with each other. Since thorough details of the fundamental algorithm can be found in the literature (e.g., Potyondy and Cundall, 2004), only a general summary is described.

For the bonded grains, the increment of the normal force $d f_{n b}$, tangential force $d f_{s b}$, and the moment $d M_{b}$ can be calculated based on the relative motion of the bonded grains, and are given as:

$$
\begin{gathered}
d f_{n b}=K_{n b}\left(d n_{j}-d n_{i}\right) \\
d f_{s b}=K_{s b}\left(d s_{j}-d s_{i}-\frac{L}{2}\left(d \theta_{i}+d \theta_{j}\right)\right) \\
d M_{b}=K_{\theta}\left(d \theta_{j}-d \theta_{i}\right)
\end{gathered}
$$

where $\mathrm{K}_{\mathrm{nb}}, \mathrm{K}_{\mathrm{sb}}$ and $\mathrm{K}_{\theta}$ are the normal, shear, and rotational stiffness of parallel bond, respectively; dn, ds, and $\mathrm{d} \theta$ are normal, shear displacement and rotation of grains; $\mathrm{L}$ is the bond length. Subscripts $\mathrm{i}$ and $\mathrm{j}$ are indices of grains. The bond length $\mathrm{L}$ and diameter $\mathrm{D}$ could be given by

$$
\begin{aligned}
& L=r_{i}+r_{j}, \\
& D=\frac{4 r_{i} r_{j}}{r_{i}+r_{j}},
\end{aligned}
$$

where $r_{i}$ and $r_{j}$ are the radii of the grains $i$ and $j$, respectively. If the tensile stress exceeds the tensile strength $\sigma_{c}$ or the shear stress exceeds the shear strength $\tau_{\mathrm{c}}$; The bond breaks, and it is removed from the model along with its accompanying force, moment, and stiffness.

In addition to the bond behavior, the linear contact behavior is active if two grains contact each other. The corresponding increment of the normal force $d f_{n}$, tangential force $d f_{s}$, and the moment $d M$ can be calculated by: 


$$
\begin{gathered}
d f_{n}=K_{n}\left(d n_{j}-d n_{i}\right) \\
d f_{s}=K_{s}\left(d s_{j}-d s_{i}-\left(r_{i} d \theta_{i}+r_{j} d \theta_{j}\right)\right) \\
d M=r_{i} d f_{s}
\end{gathered}
$$

where $K_{n}$ and $K_{s}$ are the normal and shear stiffness of contact, respectively. Since the DEM is a fully dynamic formulation, some form of damping is necessary to dissipate kinetic energy, the damping force in normal and shear directions can correspondingly be computed by the following equations:

$$
\begin{gathered}
f_{n d}=C_{n} \frac{\left(d n_{j}-d n_{i}\right)}{d t}, \\
f_{s d}=C_{s} \frac{\left(d s_{j}-d s_{i}-\left(r_{i} d \theta_{i}+r_{j} d \theta_{j}\right)\right)}{d t},
\end{gathered}
$$

where $\mathrm{dt}$ is the time step, the damping coefficient $\mathrm{C}_{\mathrm{n}}$ and $\mathrm{C}_{\mathrm{s}}$ that are calculated by:

$$
\begin{aligned}
C_{n} & =2 \sqrt{K_{n} \frac{m_{i} m_{j}}{m_{i}+m_{j}}}, \\
C_{s} & =2 \sqrt{K_{s} \frac{m_{i} m_{j}}{m_{i}+m_{j}}},
\end{aligned}
$$

where $\mathrm{m}$ is the mass of grains.

\subsection{Numerical algorithm considering thermal expansion behavior}

In EGS, the target rock has a high temperature, usually larger than $300{ }^{\circ} \mathrm{C}$. Under such an exceeding environment, the mechanical behaviors of rock change greatly compared with the normal temperature state. Based on the experimental results obtained by Yang et al. (2017), these differences are mainly caused by different thermal-expansion behaviors of various mineral grains such as quartz, feldspar, biotite, or any other minerals contained in reservoir rocks. In addition, the mechanical properties of the mineral grains themselves will also accordingly change with the increase in temperature.

For incorporating the above thermal effects in the DEM simulation process, we consider the generation of thermally-induced fractures with an algorithm different from the bond damage determination in the conventional DEM. A damage variable $\mathrm{D}$ is introduced for the new mechanism: $\mathrm{D}$ ranges from zero for an intact bond of no damage to the unity for a completely damaged bond. An exponential form applies to the damage variable D to express a smooth transition between the intact and broken bonds expressed by the following equation: 


$$
\mathrm{D}=1-\mathrm{e}^{-\left(\frac{\varepsilon_{\mathrm{n}}-\varepsilon_{\mathrm{n}}^{\mathrm{u}}}{\varepsilon_{\mathrm{n}}^{\mathrm{u}}}+\frac{\varepsilon_{\mathrm{S}}-\varepsilon_{\mathrm{s}}^{\mathrm{u}}}{\varepsilon_{\mathrm{s}}^{\mathrm{u}}}\right)}
$$

where $\varepsilon_{\mathrm{n}}$ and $\varepsilon_{\mathrm{n}}^{\mathrm{u}}$ is the total strain and elastic ultimate strain in the normal direction, respectively; $\varepsilon_{\mathrm{s}}$ and $\varepsilon_{\mathrm{s}}^{\mathrm{u}}$ is the total strain and elastic ultimate strain in shear direction, respectively. The following equations can calculate the strain between grains. Here, $\varepsilon_{\mathrm{n}}^{\mathrm{u}}$ and $\varepsilon_{\mathrm{s}}^{\mathrm{u}}$ respectively correspond to the tensile and shear strength of the bond, while $\varepsilon_{\mathrm{n}}$ and $\varepsilon_{\mathrm{s}}$ are the maximum tensile strain in the normal direction and the maximum shear strain in the tangential direction of the bond, respectively.

Then, the strength and stiffness of the bond are updated by multiplying the damage variable so that the bonds are gradually damaged with the increase in strain shown as follows:

$$
\begin{gathered}
\sigma^{c}=\sigma^{c}(1-\mathrm{D}), \\
\tau^{c}=\tau^{c}(1-\mathrm{D}), \\
K_{n}=K_{n}(1-\mathrm{D}), \\
K_{s}=K_{s}(1-\mathrm{D}) .
\end{gathered}
$$

Considering the different thermal expansion behavior of mineral grains in real rocks, different thermal expansion coefficients $\alpha$ are assigned to DEM grains randomly so that the grain radius changes with the temperature by the following equation:

$$
r_{i}^{T}=r_{i}^{0}+\alpha_{i} \Delta T r_{i}^{0}
$$

where $\mathrm{r}_{\mathrm{i}}^{\mathrm{T}}$ and $\mathrm{r}_{\mathrm{i}}^{0}$ are the radius of grain $\mathrm{i}$ when its temperature is $\mathrm{T}$ and room temperature $\left(25^{\circ} \mathrm{C}\right)$, respectively, $\alpha_{i}$ is the thermal expansion coefficient of grain $\mathrm{i}, \Delta \mathrm{T}$ is the temperature change. The thermal expansion or shrinkage of grains also generated thermal stresses causing the forces between the grains in the DEM model.

As the temperature rises, the strength of the bond will increase to simulate the increasing mutual attraction between mineral grains:

$$
\begin{aligned}
& \sigma_{T}^{c}=\sigma^{c}\left(1+\gamma_{\mathrm{T} 1} \mathrm{~T}\right), \\
& \tau_{T}^{c}=\tau^{c}\left(1+\gamma_{\mathrm{T} 1} \mathrm{~T}\right),
\end{aligned}
$$

where $\gamma_{\mathrm{T} 1}$ is a coefficient, which is set to be $0.0005, \mathrm{~T}$ is the temperature, $\sigma_{T}^{c}$ and $\tau_{T}^{c}$ are the bond strength at temperature $\mathrm{T}\left({ }^{\circ} \mathrm{C}\right)$. In these equations, when $\mathrm{T}$ is greater than the threshold temperature $\left(300^{\circ} \mathrm{C}\right.$ in this paper $), \mathrm{T}$ takes $300{ }^{\circ} \mathrm{C}$.

Chemical changes and transgranular cracks for the temperature higher than the threshold temperature, a coefficient $\gamma_{\mathrm{T} 2}$ is introduced to update the contact stiffness of the grains (which is not applied to the stiffness of 
bond, because the thermal stress caused by grain thermal expansion will lead to varying degrees of bond damage (the value of $\mathrm{D}$ is no longer 0 ), that is to say, the damage behavior of the bond at high temperature has been considered):

$$
\begin{aligned}
& K_{n}^{T}=K_{n}\left(1-\gamma_{\mathrm{T} 2}(\mathrm{~T}-300)\right), \\
& K_{s}^{T}=K_{s}\left(1-\gamma_{\mathrm{T} 2}(\mathrm{~T}-300)\right),
\end{aligned}
$$

where $K_{n}^{T}$ and $K_{s}^{T}$ are the updated normal and shear contact stiffness at temperature T, respectively.

In this paper, the relationship between thermal expansion coefficient and temperature is simplified as a linear relationship. When the temperature is lower than the threshold degree, the thermal expansion coefficient remains unchanged, while when the temperature is higher than the threshold degree, the thermal expansion coefficient increases linearly with temperature shown in the following:

$$
\tilde{\alpha}_{i}=\alpha_{i}+k_{i}^{t} \Delta \mathrm{T}
$$

where $\mathrm{k}_{\mathrm{i}}^{\mathrm{t}}$ is a coefficient, which is constantly selected to be 0.75 in this paper.

In addition, considering the size of large pores and thermal stress cracks in the actual rock induced by thermal stress, an extra gap is added to completely broken bonds (damage variable D is greater than 0.999), then the updated normal initial distance between two grains is given as follows:

$$
G_{i j}^{T}=G_{i j}^{0}+K_{g a p}\left(r_{i}+r_{j}\right)
$$

where $\mathrm{G}_{\mathrm{ij}}^{\mathrm{T}}$ and $\mathrm{G}_{\mathrm{ij}}^{0}$ are the gap between grains $\mathrm{i}$ and $\mathrm{j}$ at temperature $\mathrm{T}$ and the room temperature, respectively, $\mathrm{K}_{\mathrm{gap}}$ is the gap coefficient. The premise of applying this formula is that the bond between grains $\mathrm{i}$ and $\mathrm{j}$ has completely broken.

For a micro crack with the initial gap, the contact force between corresponding grains is zero until they move a distance towards each other greater than the initial gap.

\subsection{Brittle-ductile transition algorithm}

As one of the common types of heat storage rocks (Lu and Wang, 2015), granite exhibits typical brittleness under normal temperature and confining pressure. However, laboratory test results show that as the confining pressure increases, the mechanical behavior of granite gradually transits from brittle to ductile. In the practical implementation, it is necessary to consider the influence of the high confining pressure on the rock mechanical behavior since the rock formation in EGS has a buried depth of several kilometers. 
For general rock specimen, both the strength and stiffness gradually reduce their values as fracture develops, which is called degradation. Laboratory results suggest that this degradation behavior changes significantly with confining pressure (Brady and Brown, 1992). Specifically, the strength and stiffness degrade sharply after the peak stress in the uniaxial compression case, which shows a typical brittle behavior. As confining pressure increases, the degradation of the strength and stiffness is suppressed, and the rock displays less brittle behavior. Finally, under high confining pressure, the rock becomes fully ductile, no degradation occurs. Fang and Harrison (2001) simplified this brittle to ductile transition behavior with a degradation index, as given by Equation 13. Although the original work in Fang and Harrison (2001) was incorporated into a numerical method with a continuum approach (Fang and Harrison, 2002), we apply the idea of them to DEM calculation.

$$
\gamma_{d}=\frac{\delta \sigma}{\delta \sigma_{h}}
$$

where $\delta \sigma$ is the degradation of rock strength when subjected to a certain confining pressure, $\delta \sigma_{\mathrm{h}}$ is the corresponding hypothetical degradation if the strength degradation behaves like a uniaxial case. This degradation index is closely related to the confining pressure, as summarized by Fang and Harrison (2001).

In this paper, degradation behavior under different confining pressures is considered by updating the damage variable D:

$$
\widetilde{\mathrm{D}}=\mathrm{D} \gamma_{d}
$$

where $\widetilde{\mathrm{D}}$ is the updated damage variable. The degradation index is given by an exponential form to ensure a smooth transition from brittle to ductile as follows:

$$
\gamma_{\mathrm{d}}=\mathrm{e}^{-\mathrm{n}_{\mathrm{d}} \sigma_{3}}
$$

where $\sigma_{3}$ (Unit: $\left.\mathrm{MPa}\right)$ is the confining pressure, $\mathrm{n}_{\mathrm{d}}$ is the degradation parameter that can be estimated from experimental data. As the confining pressure on the bond increases, $\gamma_{d}$ decreases from 1 to nearly 0 , which indicates that the increment of the confining pressure suppresses the damage of bonds.

\subsection{Fluid-solid-thermal coupling algorithm}

A channel-domain model (Shimizu et al., 2011) is introduced into the proposed scheme to reproduce the fluidsolid interaction in hydraulic fracturing, as illustrated in Fig. 1: 


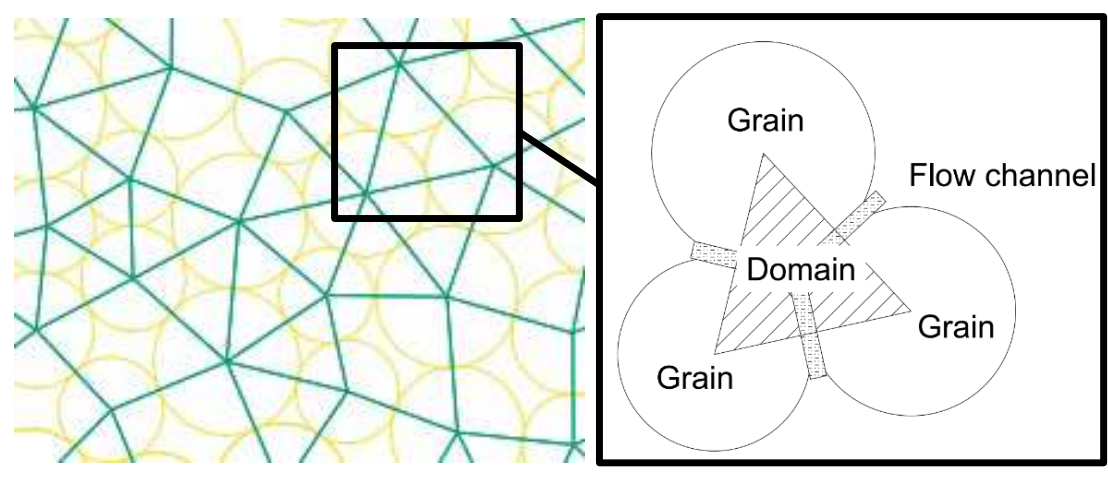

Fig. 1. Channel-domain model, domains are represented as the area enclosed by solid green lines. Yellow circles represent grains.

In the channel-domain model, the closed area enclosed by the grains is called a domain, and the fluid-solid coupling is achieved through the mutual relationship between domains and grains. In a two-dimensional DEM, every three or more grains will form a domain. The following algorithm is proposed to accommodate these domains in the computation:

Step 1: Randomly select a grain $\mathrm{i}$, randomly select a grain $\mathrm{j}$ in contact with it, and randomly select a grain $\mathrm{k}$ in contact with the grain $\mathrm{j}$ (except for the grain i). At this time, the vector from the grain $\mathrm{i}$ to the grain $\mathrm{j}$ and then to the grain $\mathrm{k}$ will be clockwise or counterclockwise; then select a grain with the same direction from the grains in contact with grain $\mathrm{k}$;

Step 2: When there are multiple grains in contact with grain $\mathrm{k}$ that meet the above condition, select the grain that forms the smallest angle, then continue to select grains using the same principle;

Step 3: Repeat steps 2 until a closed-loop (domain) is formed;

Step 4: Repeat the above steps until all grains are traversed. The corresponding result is shown in Fig. 1.

Then fluid can flow between the formed domains through the aperture, called the flow channel, between the adjoining grains. Corresponding laminar flow rate is given by the following equation based on the Poiseuille flow:

$$
\mathrm{Q}_{f}=\frac{\mathrm{w}^{3}}{12 \mu} \frac{\Delta \mathrm{P}}{\mathrm{L}_{\mathrm{c}}}
$$

where $\mathrm{Q}_{f}$ is the flow rate, $\Delta \mathrm{P}$ is the change in pressure across a channel, $\mathrm{L}_{c}$ is the length of the channel, $\mu$ is the viscosity of the fluid, and $\mathrm{w}$ is the aperture of the channel. In addition, to ensure the fluid can still pass through a model with no cracks, an initial aperture $\mathrm{w}_{0}$ is introduced so that the aperture of the closed channel could be obtained by: 


$$
\mathrm{W}=\frac{\mathrm{w}_{0} \mathrm{~F}_{0}}{\mathrm{~F}+\mathrm{F}_{0}}
$$

where $\mathrm{F}$ is the compressive normal force acting on the channel and $\mathrm{F}_{0}$ is the normal force at which the channel aperture decreases to half of its residual aperture (Al-Busaidi et al., 2005).

When the volume of fluid injected into the domain is greater than the volume of the pore $\left(\mathrm{V}_{\text {pore }}\right)$ between grains, the water pressure in the domain will start to rise from zero:

$$
\mathrm{dP}=\frac{\mathrm{K}_{\mathrm{f}}}{\mathrm{V}_{\mathrm{r}}}\left(\sum \mathrm{Q}_{f} \mathrm{dt}-\mathrm{d} \mathrm{V}_{\mathrm{r}}\right)
$$

where $\sum \mathrm{Q}_{f}$ is the total flow rate for a one-time step from the surrounding channels, $\mathrm{K}_{\mathrm{f}}$ is the fluid bulk modulus, $V_{r}$ is the apparent volume of the domain (the area of the polygonal area enclosed by the centerline of grains), and $\mathrm{dV}_{\mathrm{r}}$ is the change of the volume in the domain.

Each domain accumulates the fluid pressure. A domain with a fluid pressure $\mathrm{P}$ causes the total force $f_{d}$, given in the following equation, that acts on the surrounding grains:

$$
f_{d}=\int P \cos \theta \mathrm{r} \mathrm{d} \theta
$$

In addition, when fluid flows through a channel, shear stress will be induced. The corresponding force that acts on the surface of two grains forms a channel that can be obtained by:

$$
f_{c}=\frac{\mathrm{w}}{2} \Delta \mathrm{P}
$$

The porosity of the DEM model is much larger than the actual rock. For example, in 2-D cases, the overall porosity of the numerical model is suggested to be $16 \%$ (Potyondy and Cundall, 2004), but the porosity of granite is smaller than $1 \%$ at room temperature. An assumed porosity $\varphi$ is applied correspondingly (Shimizu et al., 2011) so that the pore volume could be calculated:

$$
\mathrm{V}_{\text {pore }}=\varphi \mathrm{V}_{\mathrm{r}}
$$

Here $\varphi$ is a parameter regarding the porosity. Considering the thermal expansion behavior of grains induced by the high temperature treatment, a temperature correction term is introduced by:

$$
\varphi_{\mathrm{T}}=\left(1.0-\gamma_{\mathrm{T} 3}(\mathrm{~T}-25)\right) \varphi_{0}
$$


where $\gamma_{\mathrm{T} 3}$ is a correction coefficient, which is set to be $0.00075, \varphi_{0}$ is the assumed porosity at room temperature $\left(25^{\circ} \mathrm{C}\right), \quad \varphi_{\mathrm{T}}$ is the assumed porosity at temperature $\mathrm{T}\left({ }^{\circ} \mathrm{C}\right)$.

In addition to the mechanical response of fluid-solid coupling, based on the formed grain-domain system, the heat exchange of grain-grain, grain-domain, and domain-domain are introduced:

For the heat exchange between grains, Fourier's law of heat conduction is applied:

$$
\frac{\Delta \mathrm{Q}}{\mathrm{dt}}=-\mathrm{k}_{\mathrm{t}} \mathrm{A}_{\mathrm{c}} \frac{\Delta \mathrm{T}}{\Delta \mathrm{x}}
$$

Here $\Delta \mathrm{T}$ and $\Delta \mathrm{x}$ are the temperature difference and distance between two grains, $\mathrm{Q}$ is the amount of heat thatflows through a cross-section between two grains during a time interval $\mathrm{dt}, \mathrm{k}_{\mathrm{t}}$ is the thermal conductivity coefficient (assumed independent of temperature and averaged over the surface, unit: $\frac{\mathrm{W}}{\mathrm{mK}}$ ) and the area $\mathrm{A}_{\mathrm{c}}$ of the cross-section is given by the radius of grain:

$$
\begin{aligned}
A_{c} & =\frac{4 r_{i} r_{j}}{r_{i}+r_{j}} \text { (Bonded), } \\
A_{c} & =\frac{r_{i} r_{j}}{r_{i}+r_{j}} \text { (Unbonded). }
\end{aligned}
$$

For the heat exchange between grain and domain, based on Newton's law of cooling, when there is a temperature difference between the surface of a grain and the surroundings, the heat lost from a unit area per unit time is proportional to the temperature difference expressed as follows:

$$
\frac{\mathrm{dQ}}{\mathrm{dt}}=-\mathrm{h} \mathrm{A}_{\mathrm{c}}^{\text {domain }}\left(\mathrm{T}_{\mathrm{t}}-\mathrm{T}_{\mathrm{domain}}\right)
$$

where $T_{t}$ and $T_{\text {domain }}$ are the temperature of the grain and surrounding domain (unit: $K$ ), respectively, $h$ is the surface heat transfer coefficient (assumed independent of temperature and averaged over the surface, unit: $\frac{\mathrm{W}}{\mathrm{m}^{2} \mathrm{~K}}$ ), and $A_{c}^{\text {domain }}$ is the contact area between the domain and the grain.

The heat exchange between domains takes place. When the fluid moves from one to the other domain through the channel, the grains on both sides will heat the fluid. Suppose the environment temperature of $\mathrm{T}_{\mathrm{env}}$ is a constant, the fluid temperature $T_{t}$ has the following relationship with $T_{\text {env }}$ : 


$$
\frac{\mathrm{dT}_{\mathrm{t}}}{\mathrm{dt}}=-\frac{\mathrm{hA}}{\mathrm{C}}\left(\mathrm{T}_{\mathrm{t}}-\mathrm{T}_{\mathrm{env}}\right)
$$

where $\mathrm{C}$ is the heat capacitance (unit: $\frac{\mathrm{J}}{\mathrm{Kg} \cdot \mathrm{K}}$ ) and the solution of this differential equation is given by:

$$
\mathrm{T}_{\mathrm{t}}=\mathrm{T}_{\mathrm{env}}+\left(\mathrm{T}_{0}-\mathrm{T}_{\mathrm{env}}\right) \mathrm{e}^{-\frac{\mathrm{dt} \cdot \mathrm{h} \cdot \mathrm{A}}{\mathrm{m} \cdot \mathrm{c}}}
$$

where $\mathrm{T}_{\mathrm{env}}$ is the average temperature of grains that form the channel, which is regarded as a constant during time interval dt. We notice that after the time with $\mathrm{dt}$, the fluid with an initial temperature $\mathrm{T}_{0}$ will be heated to $\mathrm{T}_{\mathrm{t}}$ under the environment temperature $\mathrm{T}_{\mathrm{env}}$. When the surrounding fluid cools grain, the channel will shrink, and extra thermal stress will be induced correspondingly.

\section{Calibration}

In this paper, Lac du Bonnet granite is selected as the object of parameter calibration because granite is a common type of rock in EGS (Lu and Wang, 2015), and Lac du Bonnet granite has publicly reliable physical parameters such as strength and Young's modulus. Uniaxial compression test, direct tensile test, and constant head permeability test are performed to calibrate model properties where the values of related model parameters are listed in Table 1:

Table 1 Micro properties of DEM model.

\begin{tabular}{|lccc|}
\hline Micro property & Symbol & Unit & Value \\
Density of grain & $\rho$ & $\mathrm{Kg} / \mathrm{m}^{3}$ & 2630 \\
Young's modulus & $\mathrm{E}$ & $\mathrm{GPa}$ & 45 \\
Stiffness ratio & $\mathrm{K}_{\mathrm{s}} / \mathrm{K}_{\mathrm{n}}$ & 0.4 & -- \\
& & & \\
Tensile strength of bond & $\sigma_{c}$ & $\mathrm{MPa}$ & 11.5 \\
Shear strength of bond & & & 110 \\
& $\tau_{\mathrm{c}}$ & $\mathrm{MPa}$ & \\
Coefficient of friction & & & 0.25 \\
\hline
\end{tabular}




\begin{tabular}{|llll|}
\hline Initial aperture & $\mathrm{w}_{0}$ & $\mathrm{~m}$ & 0.0000008 \\
Assumed porosity & $\varphi$ & $\%$ & 5 \\
Thermal conductivity coefficient & $\mathrm{k}_{\mathrm{t}}$ & $\mathrm{W} / \mathrm{mK}$ & 3.0 \\
Specific heat capacity of grain & $\mathrm{c}_{\mathrm{g}}$ & $\mathrm{J} / \mathrm{Kg} \cdot \mathrm{K}$ & 920 \\
& & & \\
\hline
\end{tabular}

During the simulation of the uniaxial compression test, a loading wall is placed above the model and moved slowly down to apply compression stress. The velocity of the wall is $0.05 \mathrm{~m} / \mathrm{s}$, which is very large in the actual experiment. Nevertheless, in the numerical simulation, since the time step is very small, the wall moving distance in each iteration is very small, which is enough to ensure the accuracy of the numerical simulation. The crack width in this paper is obtained by equation 28 . All parameters are calibrated at room temperature.

$$
\omega=\sqrt{\mathrm{D}_{n}^{2}+\mathrm{D}_{s}^{2}}
$$

where $\omega$ the crack width, $\mathrm{D}_{n}$ and $\mathrm{D}_{s}$ are the distance between the two grains in normal and shear direction, respectively. When the normal stress between these two grains is compressive stress, the value of $\mathrm{D}_{n}$ is 0 .

In the calibration process of Young's modulus and Poisson's ratio, some grains on the model are used as sensors, and their displacements will be recorded and averaged respectively to measure the axial strain and lateral strain of the specimen.

Based on the uniaxial compression test simulation, the crack distribution pattern is shown in Fig. 2 (a), from which the model presents a typical failure mode of rocks. 


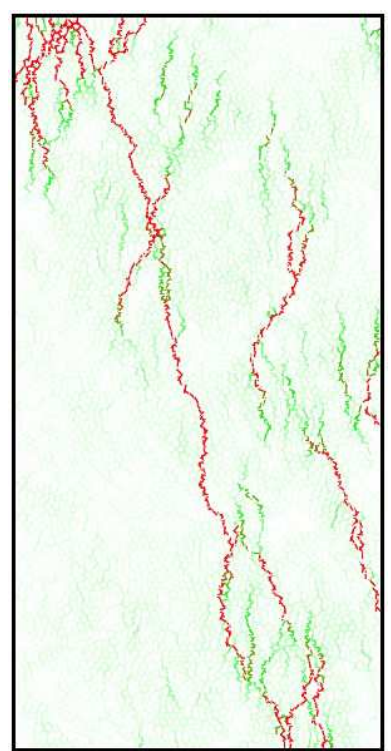

(a)

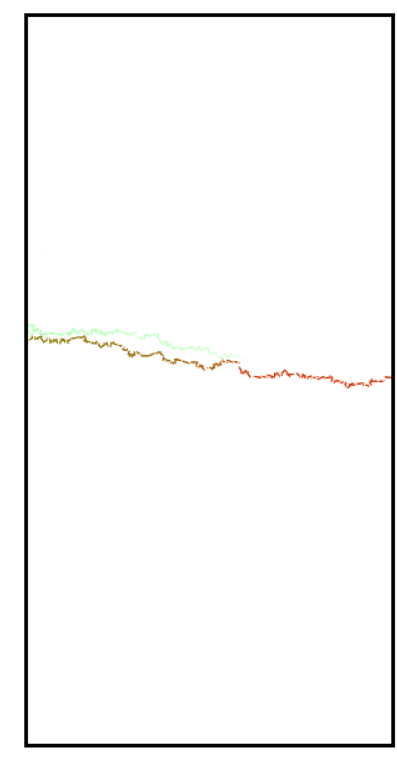

(a)
1.0

0.9

0.8

0.7

0.6

0.5

0.4

0.3

0.2

0.1

0.0

Fig. 2. Crack distribution patterns of uniaxial compression test (a) and direct tension test (b).

The lines in Fig. 2 show the distribution of cracks, and the color of the lines represents the normalized crack width.

The tensile strength of the model must be measured to verify the uniaxial compressive strength (UCS) to the tensile strength (TS) ratio (UCS/TS ratio). The direct tensile test is chosen to characterize the tensile strength since the numerical implementation is relatively straightforward and does not suffer from the difficulties encountered experimentally. The crack distribution pattern for the direct tension test is shown in Fig. 2 (b).

Based on the numerical simulation, the macro properties of the models are measured. The comparison between this numerical result and Lac du Bonnet granite is listed in Table 2. We find that the simulation results have good agreement with the laboratory experimental results.

Table 2 Comparison between the simulation result and Lac du Bonnet granite.

\begin{tabular}{|ccccc|}
\hline Property & Symbol & Unit & $\begin{array}{c}\text { Theoretical } \\
\text { value }\end{array}$ & $\begin{array}{c}\text { Simulatio } \\
\text { n result }\end{array}$ \\
$\begin{array}{c}\text { Young's } \\
\text { modulus }\end{array}$ & $E$ & $\mathrm{GPa}$ & $69 \pm 5.8$ & 66.5 \\
$\begin{array}{c}\text { Poisson's ratio } \\
\begin{array}{c}\text { Uniaxial } \\
\text { compression } \\
\text { strength }\end{array}\end{array}$ & $v$ & -- & $0.26 \pm 0.04$ & 0.28 \\
$\begin{array}{c}\text { Tensile } \\
\text { strength }\end{array}$ & $q_{t}$ & $\mathrm{MPa}$ & $200 \pm 22$ & 194.5 \\
& & $\mathrm{MPa}$ & $9.1 \pm 1.3$ & 9.5 \\
\hline
\end{tabular}


The constant head permeability test is conducted to calibrate the permeability of the model. First, the upper and lower ends of the numerical model are defined as fluid injection end and fluid outflow end, respectively. The fluid could flow in from the fluid injection end and flows out from the fluid outflow end, and the other sides of the model are set to be impervious. During the numerical simulation, the upper and lower ends of the model are given a fixed pressure difference. When the flow rates at the fluid injection and fluid outflow ends are equal, the permeability coefficient $\mathrm{k}$ of the model can be measured accordingly:

$$
\mathrm{k}=\frac{\mathrm{Q}_{\mathrm{s}}}{\mathrm{Ai}}
$$

where $Q_{s}$ is the flow rate when the model reaches stability, $A$ is the cross-sectional area of the model through which the fluid flows, and $\mathrm{i}$ is the hydraulic gradient.

The calibrated permeability coefficient of the model is $1.9 \times 10^{-12} \mathrm{~m} / \mathrm{s}$, which is in the range of published data of Lac du Bonnet granite $\left(10^{-13} \sim 10^{-4} \mathrm{~m} / \mathrm{s}\right.$, Miguel et al., 2009).

Similarly, to calibrate the thermal conductivity coefficient of the model, the grains at the lower end of the model are given with a high initial temperature $\left(100{ }^{\circ} \mathrm{C}\right.$, here does not consider the thermal expansion caused by temperature) and remain unchanged. Then, due to the uneven temperature distribution of the model, heat will be conducted from the high-temperature grains to the low-temperature grains. In this process, based on Fourier's law, the heat conductivity coefficient between a group of grains can be given by:

$$
\mathrm{k}_{\mathrm{t}}=-\frac{\Delta \mathrm{Q} \Delta \mathrm{x}}{\operatorname{Adt} \Delta \mathrm{T}}
$$

Corresponding parameters are the same as equation (21).

Fig. 3 shows the initial temperature distribution $\left({ }^{\circ} \mathrm{C}\right)$ of the model and the temperature distribution after 300,000 iterations: 


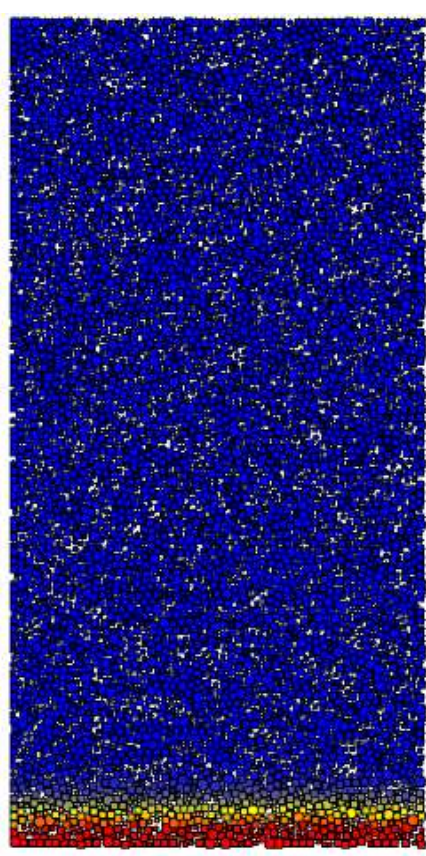

(a) Initial state

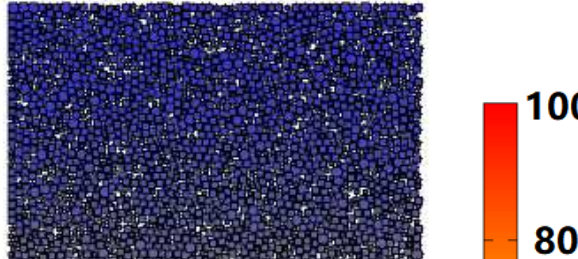

80

60

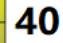

20

Fig. 3. Changes in the temperature distribution of the numerical model. Color scale represents the temperature of

grains.

We can observe the heat conduction from the high-temperature grains to the low-temperature grains after the iteration. By measuring the thermal conductivity coefficient between multiple groups of grains and taking the average value, the thermal conductivity coefficient of the model can be obtained as $3.57 \frac{\mathrm{W}}{\mathrm{mK}}$, which is in the range of granite thermal conductivity coefficient $\left(1.7 \sim 4.0 \frac{\mathrm{W}}{\mathrm{mk}}\right.$, Vazifeshenas and Sajadi, 2010).

\section{Validation of the proposed methods}

Numerical simulations of uniaxial compression tests after different temperature treatments and biaxial compression tests under different confining pressure are carried out to verify the validity of the proposed algorithm. The comparison with the experimental results is illustrated as well. The thermal treatment algorithm of the numerical model can be briefly described as follows: Firstly, the temperature of numerical specimens are increased to their target temperature $\left(200,300,400,500,600,700\right.$, and $\left.800{ }^{\circ} \mathrm{C}\right)$ at a slow rate of $0.45^{\circ} \mathrm{C} / \mathrm{min}$ to reduce the influence of the heating rate itself. In this process, the radius of the grains is expanding with the increase in temperature. After the model reaches a steady-state, the specimens are cooled to room temperature $\left(25{ }^{\circ} \mathrm{C}\right)$. Subsequently, as the decrease in temperature, the grain radius will also shrink. Through different thermal expansion coefficients, the DEM grain can simulate the different thermal expansion and contraction behavior that leads to the thermal stress and then generate the thermally induced cracks. After different thermal treatments, numerical models with initial thermal stress cracks are used for uniaxial compression tests. The stress-strain curves obtained by the above procedure are shown in Fig. 4: 


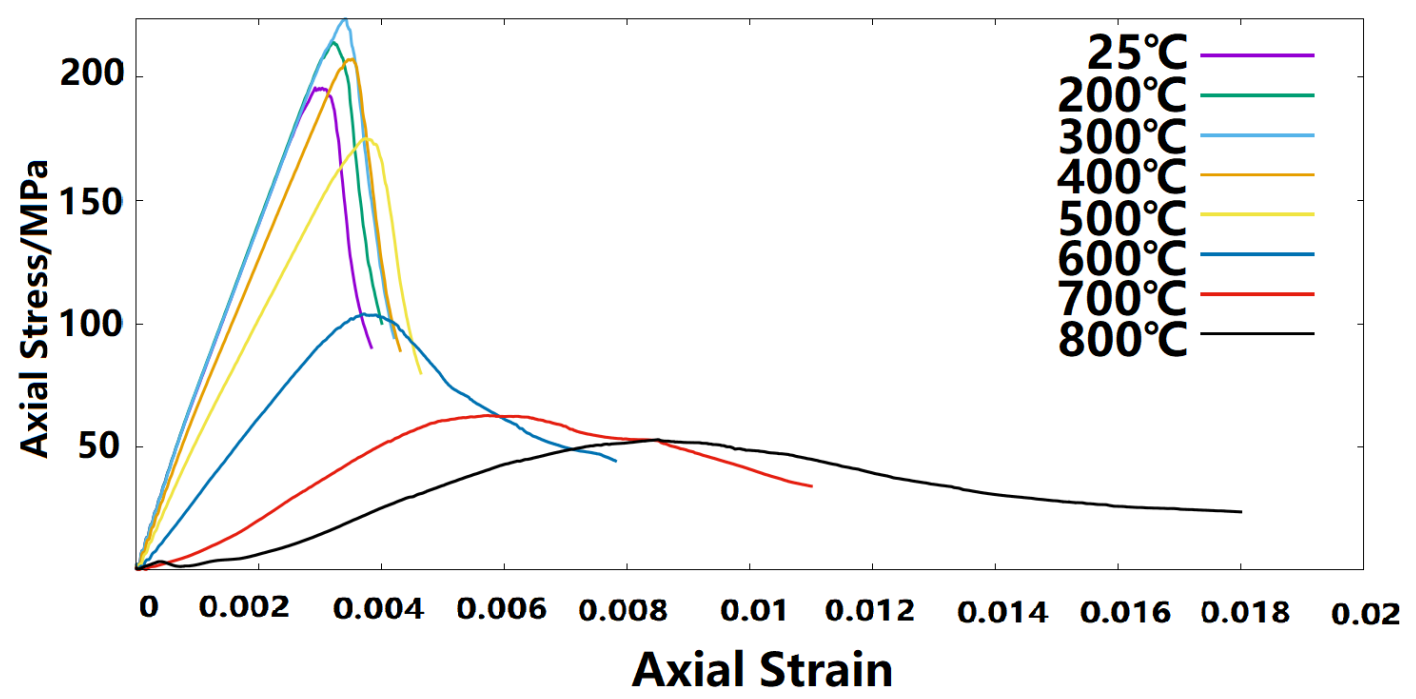

Fig. 4. Axial stress-strain curves of uniaxial compression tests under different temperatures $\left({ }^{\circ} \mathrm{C}\right)$ obtained by numerical simulation.

From Fig. 4, it can be observed that the results obtained based on the proposed algorithm have the following characteristics:

When the temperature of the specimen increases from the room temperature to $300{ }^{\circ} \mathrm{C}$, the uniaxial compressive strength is increased, the curve shows typical brittle failure characteristics; while when the temperature increases from $300{ }^{\circ} \mathrm{C}$ to $800{ }^{\circ} \mathrm{C}$, the uniaxial compressive strength and static elastic modulus of granite specimens are significantly decreased, and a more ductile failure of granite could be observed;

The peak axial strain showed an increasing trend when the temperature is increased;

The stress-strain curve exhibits non-linear at the beginning of loading; this phenomenon becomes more evident as the temperature rises, caused by the closure of thermal cracks.

These behaviors of granite specimens after different thermal treatments match very well compared with the experimental test (Yang et al., 2017). Since many scholars have carried out similar experiments, it is necessary to discuss the subtle differences briefly. In short, the difference between different experiments mainly occurs in the mild temperature range $\left(25^{\circ} \mathrm{C}-300{ }^{\circ} \mathrm{C}\right)$, when the temperature is is higher than this range, the above tests all obtained the conclusion that with the temperature increases, the strength of the specimen decreases, the peak strain increases, and the failure mode shows a tendency of brittleness-ductility transition. In the mild temperature range, some experiments showed that the strength of granite specimens increases with increasing temperature (Yang et al., 2017; Rossi et al., 2018); while some other experiments showed that the strength of the specimen decreases with the increase of temperature (Shen et al., 2020). The reasons for these differences are complex, including rock 
mineral composition, porosity, initial water content and some other factors (Wong et al., 2020). Since the rock types of the EGS heat storage rock formations are not unique, and the environment is far more complex than the laboratory environment, this paper used the threshold temperature mentioned in Equation 9 to distinguish these two cases. In addition, because the difference between these two cases is mainly concentrated in the mild temperature range, and the temperature discussed in this paper has exceeded this range, only the results considering the strength enhancement in the mild temperature range are shown. In contrast, the case where the strength and temperature are negatively correlated in the mild temperature range could be achieved by adjusting the threshold temperature in Equation 9.

In addition, the failure mode of the rock gradually changes from brittle failure to ductile failure with increasing temperature. The corresponding crack patterns of the numerical model are shown in Fig. 5:

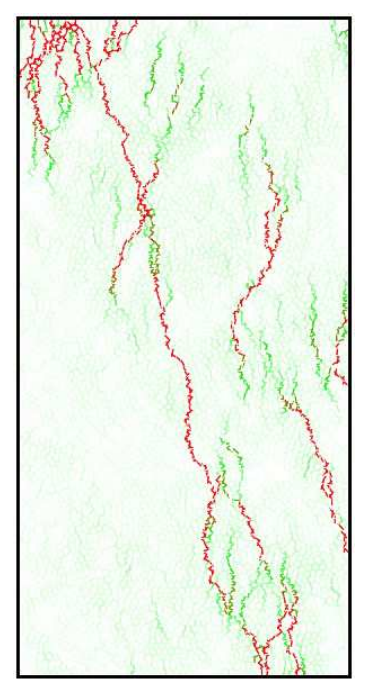

(a)

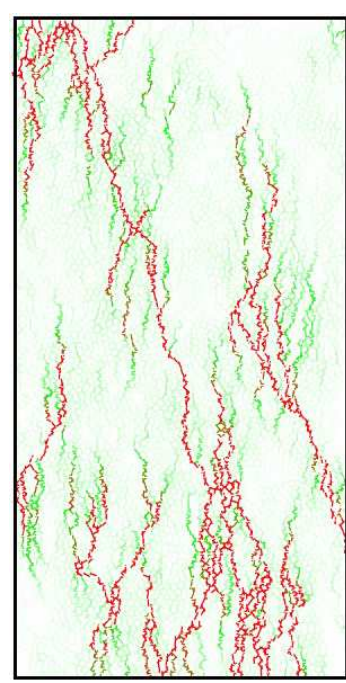

(b)

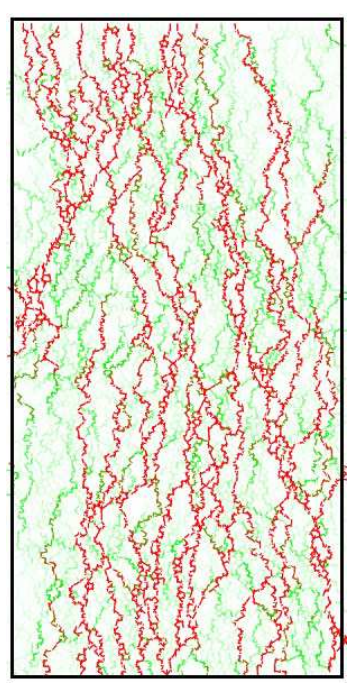

(c)

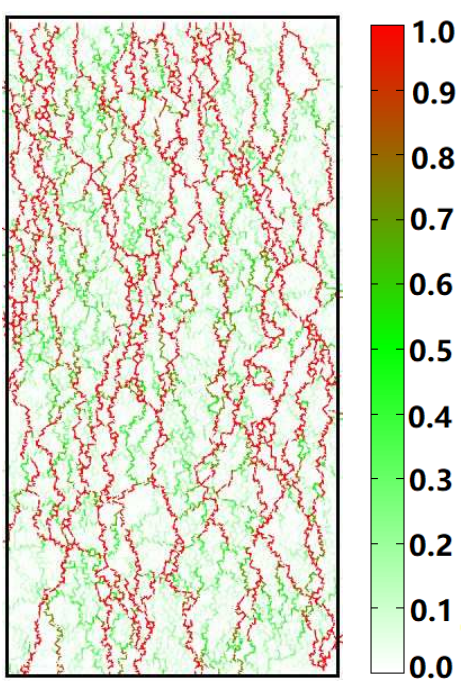

(d)

Fig. 5. Numerical model at $25^{\circ} \mathrm{C}$ (a), $300{ }^{\circ} \mathrm{C}\left(\right.$ b), $700{ }^{\circ} \mathrm{C}$ (c) and $800{ }^{\circ} \mathrm{C}$ (d) after uniaxial compression failure

It could be observed that the granite at room temperature is a kind of typically brittle rock material, showing axial splitting tensile failure mode, which is manifested as several axial tensile cracks. After the high temperature treatment, the fracture evolution process is affected by thermally induced cracks. Instead of large axial splitting tensile cracks, more shear failure along tensile cracks is observed due to thermal damage before the compression. The propagation and coalescence of thermal cracks lead to a complicated crack network, which is different from the process for specimens at lower temperatures. These phenomena are consistent with the experimental results obtained by Yang et al. (Yang et al., 2017).

Next, we investigate the effect of the confining pressure using biaxial compression tests with different confining pressure. 


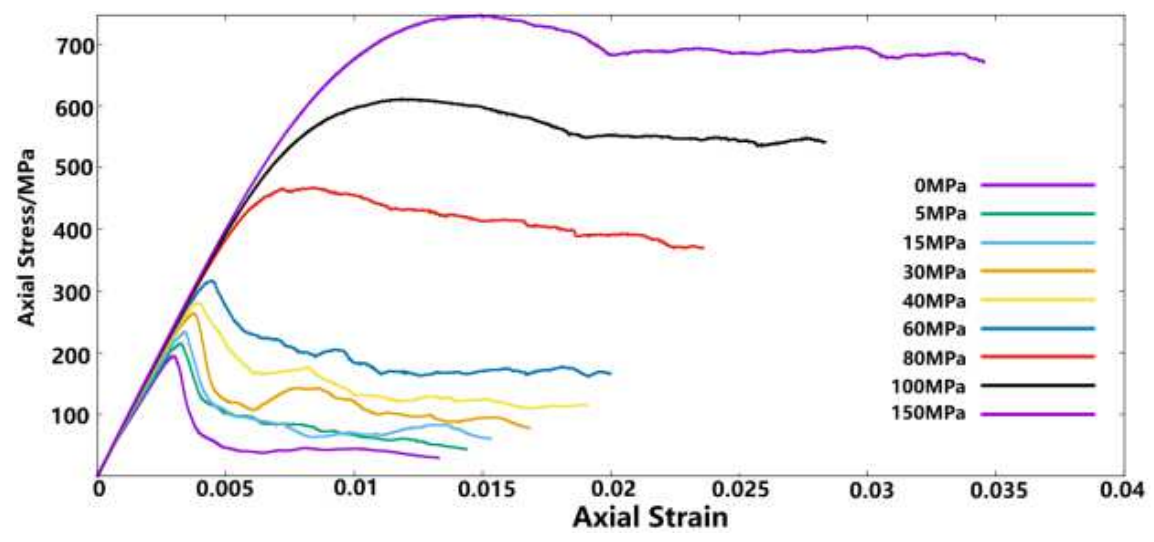

Fig. 6. Axial Stress-strain curves with different confining pressure. The vertical and horizontal axes are the axial stress and axial strain, respectively.

The stress-strain curves of biaxial tests are shown in Fig. 6. The ductility and peak strength of the numerical specimen gradually increases with increasing the confining pressure. The difference between the peak strength and post-peak residual strength decreases with increasing the confining pressure. The trend described above has good agreement with the laboratory experiments. Corresponding crack patterns of the numerical specimen with different values of the confining pressure are shown in Fig. 7:

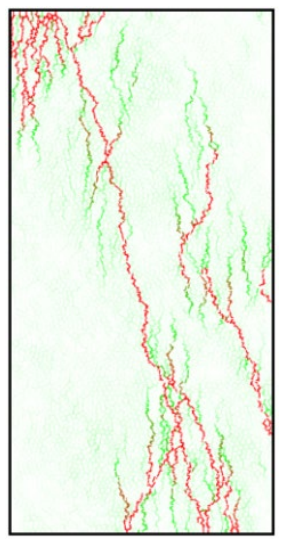

(a) Unconfined

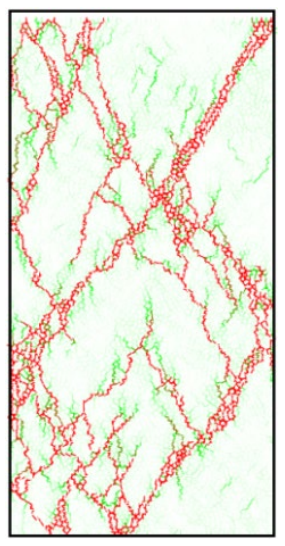

(f) $\sigma_{3}=60 \mathrm{MPa}$

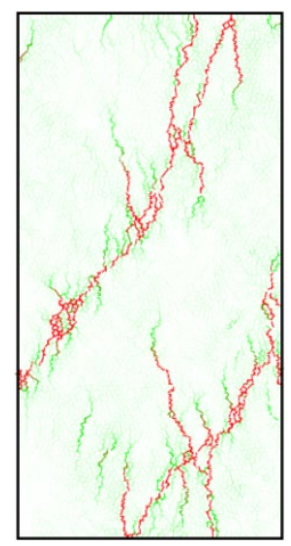

(b) $\sigma_{3}=5 \mathrm{MPa}$

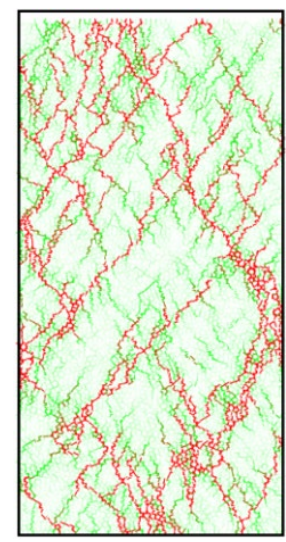

(g) $\sigma_{3}=80 \mathrm{MPa}$

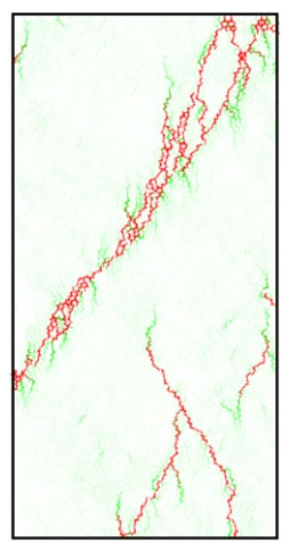

(c) $\sigma_{3}=15 \mathrm{MPa}$

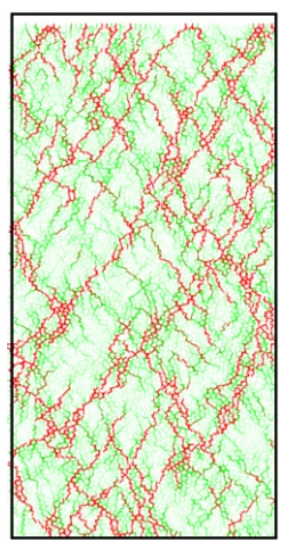

(h) $\sigma_{3}=100 \mathrm{MPa}$

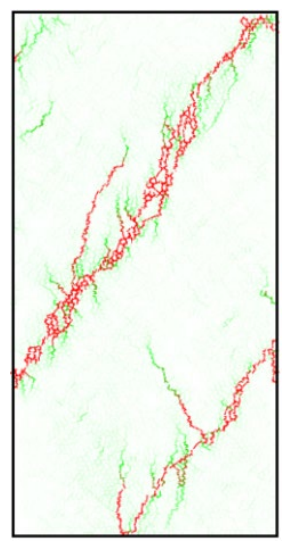

(d) $\sigma_{3}=30 \mathrm{MPa}$

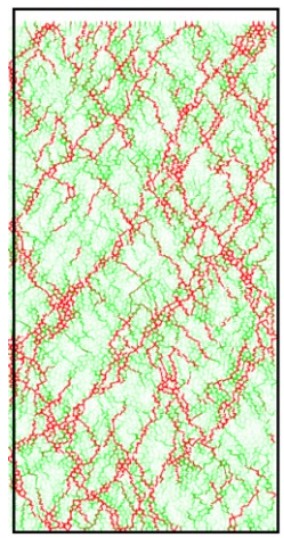

(h) $\sigma_{3}=150 \mathrm{MPa}$

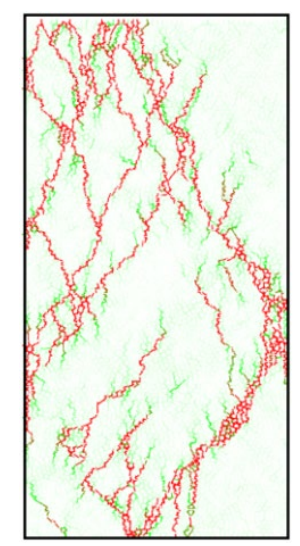

(e) $\sigma_{3}=40 \mathrm{MPa}$

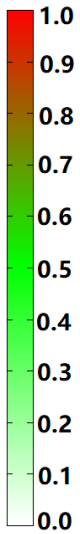

Fig. 7. Crack patterns in the numerical specimens of biaxial compression tests under different confining pressure 
Fig. 7 illustrates the crack patterns of the numerical models under different confining pressure. In the uniaxial case, several axial splitting cracks can be observed. The model shows axial splitting tensile failure mode, which is one of the main forms of brittle failure of granite under room temperature. As confining pressure increases, the number of axial splitting cracks decreases, and the shear cracks gradually dominate. Finally, shear cracks spread over the entire specimen volume under high confining pressure, which indicates that the numerical model fails under a more diffuse failure mode.

In order to characterize the proportion of tensile failure and shear failure of the specimen, this paper uses the average ratio $D_{n} / \omega$ of cracks, to represent the proportion of tensile failure. The definition of $D_{n}$ and $\omega$ could be found in Equation 28. The average ratio $\mathrm{D}_{n} / \omega$ value under different confining pressures when specimen reaches the peak stress is shown in Table 3:

Table 3 Average $\mathrm{D}_{n} / \omega$ under different confining pressure.

\begin{tabular}{|cc|}
\hline Confining pressure/MPa & Average $\mathrm{D}_{n} / \omega$ \\
0 & 0.254853094 \\
5 & 0.183682238 \\
15 & 0.129199771 \\
30 & 0.120987523 \\
40 & 0.120668218 \\
60 & 0.117995309 \\
80 & 0.116177384 \\
100 & 0.115341004 \\
150 & \\
\hline
\end{tabular}

From Table 3, as the confining pressure increases, the average value of $D_{n} / \omega$ gradually decreases, which means that the proportion of tensile failure decreases, which also verifies the transition of the specimen from a brittle failure mode to a more complex ductile failure mode.

\section{Hydraulic fracturing simulation}

The previous section confirmed that the mechanical behavior of rock under high temperature and high confining pressure could be reproduced by the proposed method. In this section, numerical simulations of hydraulic fracturing under various conditions are performed to study the combined effects of confining pressure, temperature, 
and the property of injection fluid on the results of hydraulic fracturing. Here the numerical specimens are first heated to a predetermined temperature $\left(25^{\circ} \mathrm{C}, 400^{\circ} \mathrm{C}\right.$ or $600^{\circ} \mathrm{C}$ in this paper) according to the previously mentioned thermal expansion algorithm, and then, confining pressures (5 $\mathrm{MPa}, 30 \mathrm{MPa}$ or $60 \mathrm{MPa}$ in this paper) are applied in both $\mathrm{x}$-direction and $\mathrm{y}$-direction through four frictionless walls. The microscopic mechanical parameters used in this simulation are shown in Table 4:

Table 4. Physical properties used in numerical experiments.

\begin{tabular}{|c|c|c|c|}
\hline Micro property & Symbol & Unit & Value \\
\hline Density of grain & $\rho$ & $\mathrm{Kg} / \mathrm{m}^{3}$ & 2630 \\
\hline Young's modulus & $\mathrm{E}$ & $\mathrm{GPa}$ & 45 \\
\hline Stiffness ratio & $\mathrm{K}_{\mathrm{s}} / \mathrm{K}_{\mathrm{n}}$ & -- & 0.4 \\
\hline Tensile strength of bond & $\sigma_{c}$ & $\mathrm{MPa}$ & 11.5 \\
\hline Shear strength of bond & $\tau_{\mathrm{c}}$ & $\mathrm{MPa}$ & 110 \\
\hline Coefficient of friction & $\mu_{f}$ & -- & 0.25 \\
\hline Bulk modulus of the fracturing fluid & $\mathrm{K}_{\mathrm{f}}$ & $\mathrm{GPa}$ & 2.0 \\
\hline Assumed porosity & $\varphi$ & $\%$ & 0.5 \\
\hline Thermal conductivity coefficient & $\mathrm{k}_{\mathrm{t}}$ & $\mathrm{W} / \mathrm{mK}$ & 3.0 \\
\hline Specific heat capacity of grain & $\mathrm{c}_{\mathrm{g}}$ & $\mathrm{J} / \mathrm{Kg} \cdot \mathrm{K}$ & 920 \\
\hline Specific heat capacity of fluid & $\mathrm{c}_{\mathrm{f}}$ & $\mathrm{J} / \mathrm{Kg} \cdot \mathrm{K}$ & 4200 \\
\hline Surface heat transfer coefficient & h & $\frac{W}{m^{2} K}$ & 5000 \\
\hline Fluid density & $\rho_{\mathrm{f}}$ & $\mathrm{Kg} / \mathrm{m}^{3}$ & 1000 \\
\hline Temperature of injection fluid & $T_{f}$ & ${ }^{\circ} \mathrm{C}$ & 25 \\
\hline
\end{tabular}




\begin{tabular}{|llll|}
\hline $\begin{array}{l}\text { Maximum thermal expansion } \\
\text { coefficient at room temperature }\end{array}$ & $\alpha_{i}^{\max }$ & $K^{-1}$ & 0.000006 \\
Average thermal expansion & & & \\
coefficient at room temperature & $\alpha_{i}^{\text {ave }}$ & $K^{-1}$ & 0.000003 \\
Minimum thermal expansion & & & \\
coefficient at room temperature & $\alpha_{i}^{\min }$ & $K^{-1}$ & 0.0000001 \\
& & & \\
\end{tabular}

When the injection fluid viscosity is $0.1 \mathrm{mPa} . \mathrm{s}$, the crack patterns and corresponding evolution of borehole pressure of hydraulic fracturing at different temperature are shown in Fig. 8 - 9:
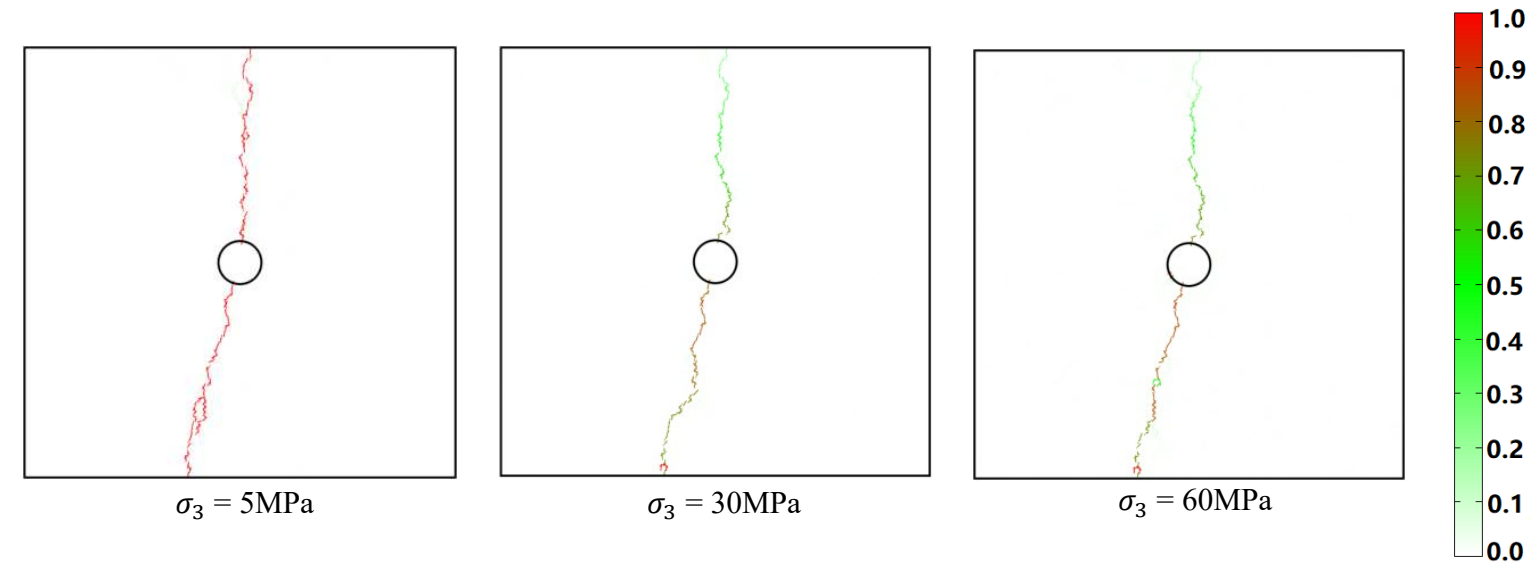

Fig. 8. Crack patterns when the injection fluid viscosity is $0.1 \mathrm{mPa}$.s at room temperature.

From Fig. 8, it can be observed that the development of hydraulic fractures is suppressed with increasing confining pressure, which is manifested as a decrease in crack width and few hydraulic cracks.

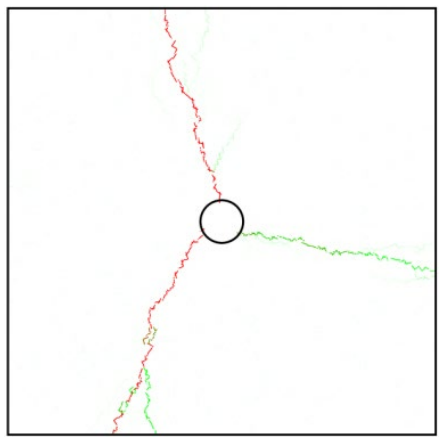

$\sigma_{3}=5 \mathrm{MPa}, \mathrm{T}=400^{\circ} \mathrm{C}$

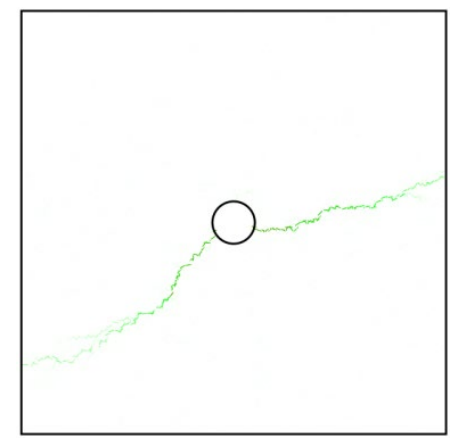

$\sigma_{3}=30 \mathrm{MPa}, \mathrm{T}=400{ }^{\circ} \mathrm{C}$

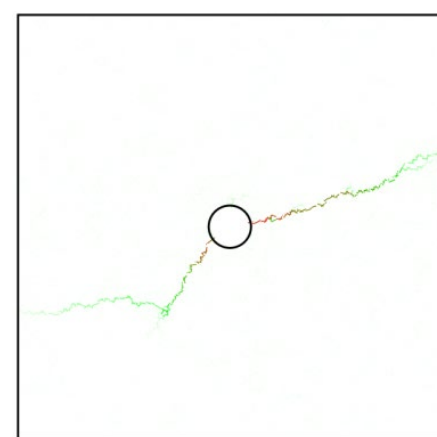

$\sigma_{3}=60 \mathrm{MPa}, \mathrm{T}=400{ }^{\circ} \mathrm{C}$

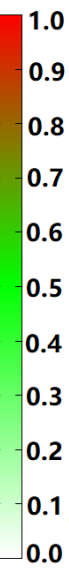




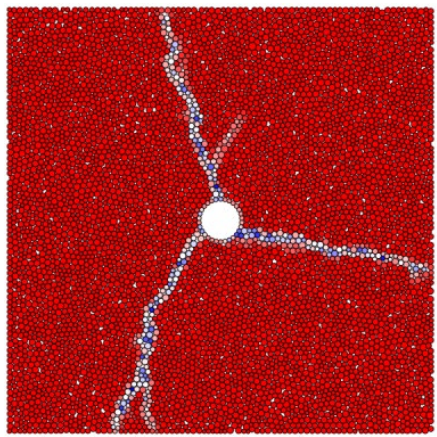

$\sigma_{3}=5 \mathrm{MPa}, \mathrm{T}=400^{\circ} \mathrm{C}$

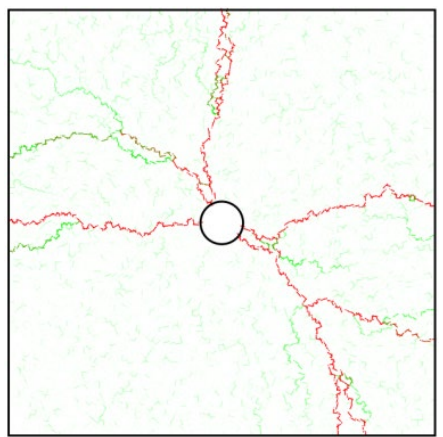

$\sigma_{3}=5 \mathrm{MPa}, \mathrm{T}=600{ }^{\circ} \mathrm{C}$

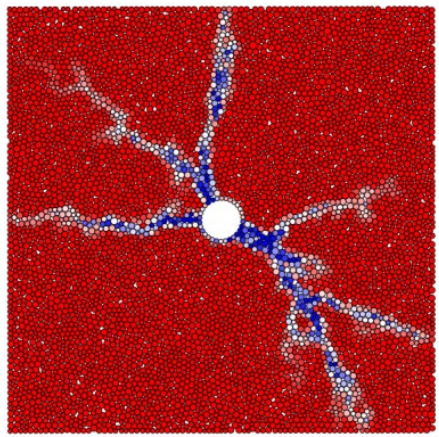

$\sigma_{3}=5 \mathrm{MPa}, \mathrm{T}=600{ }^{\circ} \mathrm{C}$

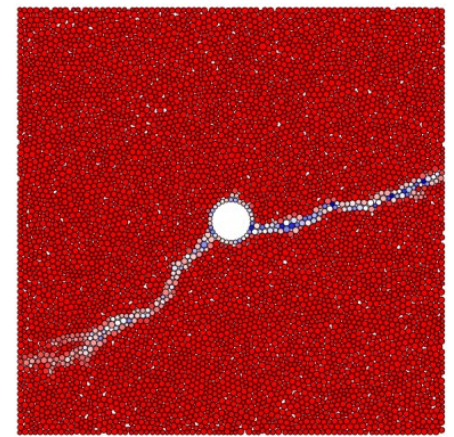

$\sigma_{3}=30 \mathrm{MPa}, \mathrm{T}=400{ }^{\circ} \mathrm{C}$

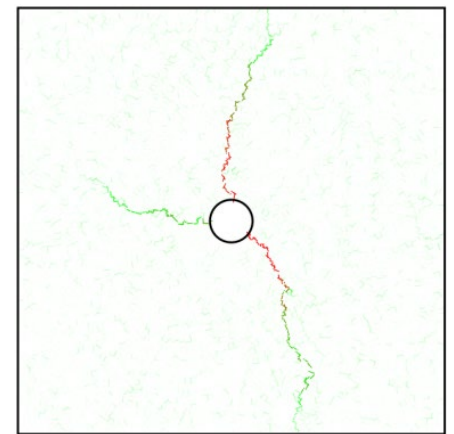

$\sigma_{3}=30 \mathrm{MPa}, \mathrm{T}=600^{\circ} \mathrm{C}$

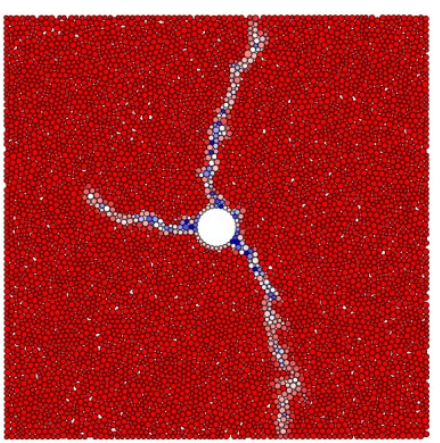

$\sigma_{3}=30 \mathrm{MPa}, \mathrm{T}=600^{\circ} \mathrm{C}$

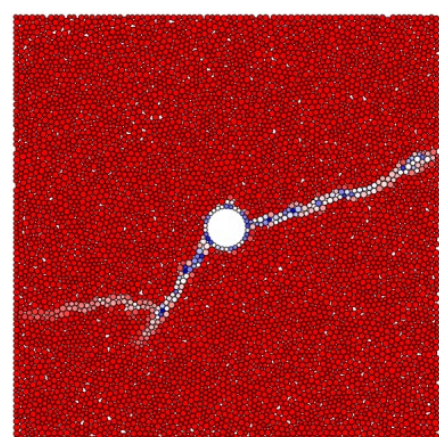

$\sigma_{3}=60 \mathrm{MPa}, \mathrm{T}=400^{\circ} \mathrm{C}$

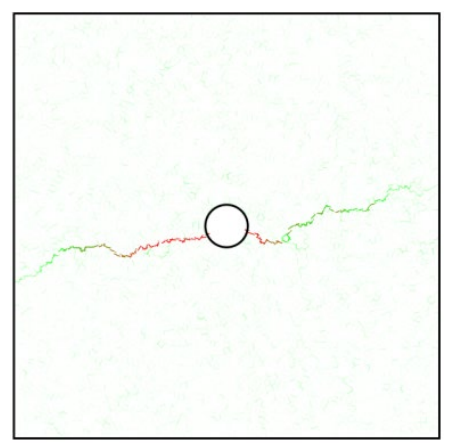

$\sigma_{3}=60 \mathrm{MPa}, \mathrm{T}=600{ }^{\circ} \mathrm{C}$

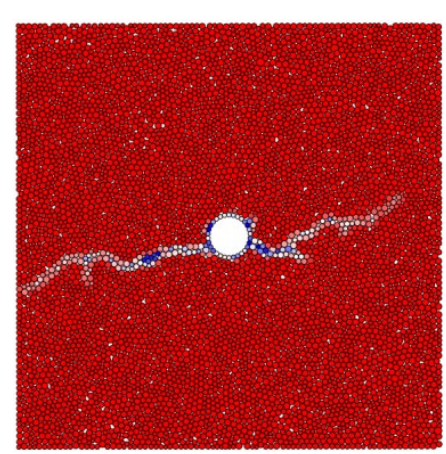

$\sigma_{3}=60 \mathrm{MPa}, \mathrm{T}=600^{\circ} \mathrm{C}$
400

398

396

394

392

390

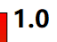

0.9

0.8

0.7

$-0.6$

0.5

0.4

0.3

0.2

0.1

0.0

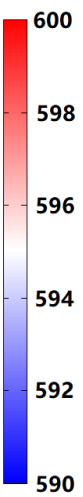

Fig. 9. The crack patterns and corresponding temperature distribution $\left({ }^{\circ} \mathrm{C}\right)$ when the injection fluid viscosity is $0.1 \mathrm{mPa} . \mathrm{s}$ at $400^{\circ} \mathrm{C}$ and $600^{\circ} \mathrm{C}$.

From Fig. 9, compared with the room temperature, when the temperature is $400^{\circ} \mathrm{C}$ and $600^{\circ} \mathrm{C}$, more hydraulic fractures can be observed under the confining pressure of 5MPa. When the confining pressure is 30 or $60 \mathrm{MPa}$, although the propagating direction of hydraulic fractures has changed due to initial thermal stress cracks induced by thermal expansion, the number of hydraulic fractures has not changed significantly.

At different temperature, the relationship between the average crack width and the confining pressure when the borehole pressure reaches stabilized pressure is summarized in Table 5: 
Table 5 Average crack width under different confining pressure and temperature.

\begin{tabular}{|c|c|c|c|}
\hline Confining pressure/MPa & 5 & 30 & 60 \\
\hline 25 & 0.0000035 & 0.00000067 & 0.00000092 \\
\hline 400 & 0.0000015 & 0.00000066 & 0.00000087 \\
\hline 600 & 0.0000071 & 0.0000022 & 0.0000019 \\
\hline
\end{tabular}

As the confining pressure increases, the average crack width tends to decrease regardless of temperature.

When the confining pressure is kept constant, the average crack width at $400^{\circ} \mathrm{C}$ is smaller than that at $25^{\circ} \mathrm{C}$. Although the initial thermal stress cracks help induce more hydraulic cracks, the thermal expansion of grains causes a decrease in crack width and causes the temperature-dependent crack-width. When the temperature is $600^{\circ} \mathrm{C}$, the influence of initial thermal stress cracks on the average crack width far exceeds the thermal expansion of grains, so the average crack width at $600^{\circ} \mathrm{C}$ is more significant than that at room temperature.

When the injection fluid has high viscosity $(100.0 \mathrm{mPa} . \mathrm{s})$, numerical results with different confining pressure and temperature are obtained, as shown in Fig. 10 - 11:

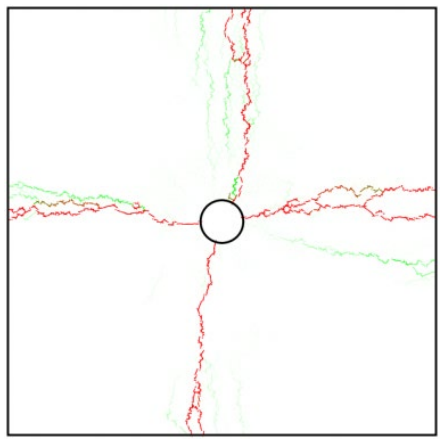

$\sigma_{3}=5 \mathrm{MPa}$

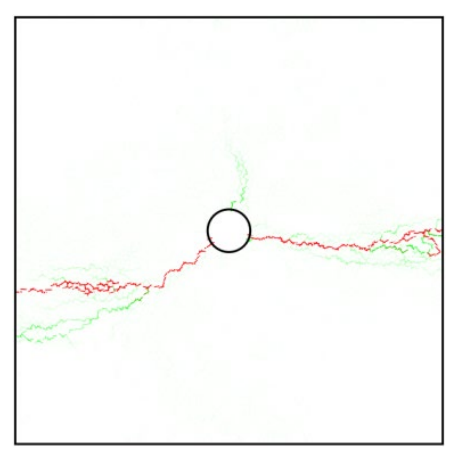

$\sigma_{3}=30 \mathrm{MPa}$

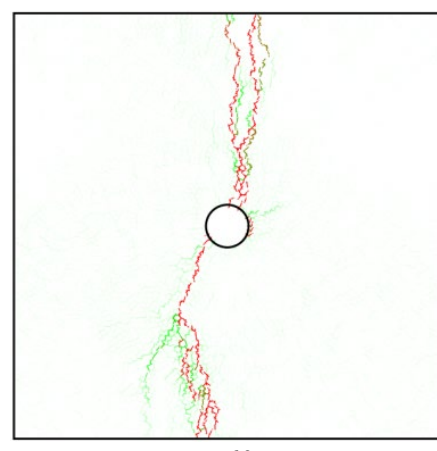

$\sigma_{3}=60 \mathrm{MPa}$

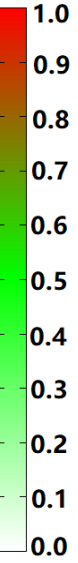

1.0 0.8 0.6 0.5 0.4 0.3 0.1

Fig. 10. Crack patterns when the injection fluid viscosity is $100 \mathrm{mPa} . \mathrm{s}$ at room temperature.

From Fig. 10, it could be observed that the development of hydraulic fractures is suppressed with increasing confining pressure, and high viscosity fluid induces more hydraulic cracks under 5MPa confining pressure. When the confining pressure is $30 \mathrm{MPa}$ and $60 \mathrm{MPa}$, although the development of cracks is suppressed due to high confining pressure, high-viscosity fluids still tend to induce more hydraulic cracks. 


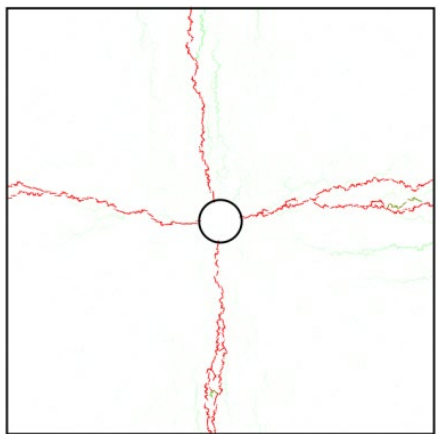

$\sigma_{3}=5 \mathrm{MPa}, \mathrm{T}=400{ }^{\circ} \mathrm{C}$

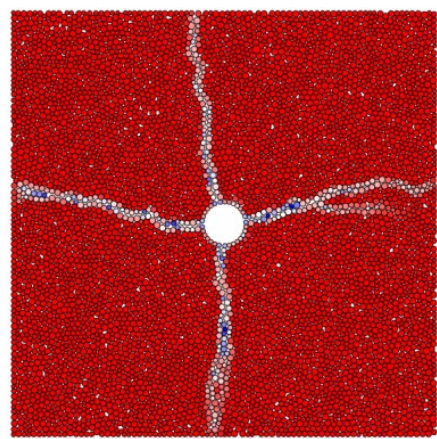

$\sigma_{3}=5 \mathrm{MPa}, \mathrm{T}=400{ }^{\circ} \mathrm{C}$

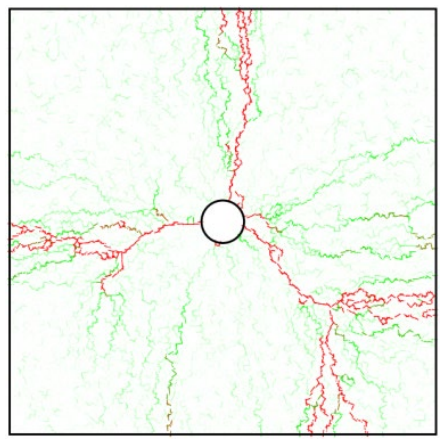

$\sigma_{3}=5 \mathrm{MPa}, \mathrm{T}=600^{\circ} \mathrm{C}$

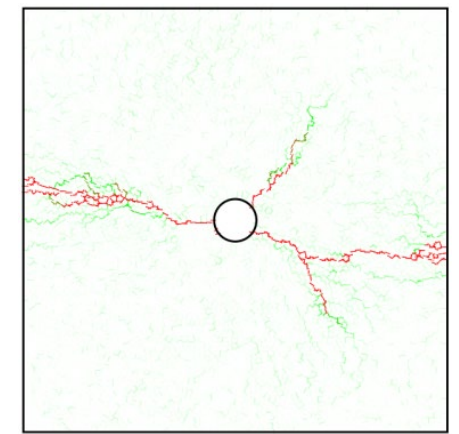

$\sigma_{3}=30 \mathrm{MPa}, \mathrm{T}=600{ }^{\circ} \mathrm{C}$

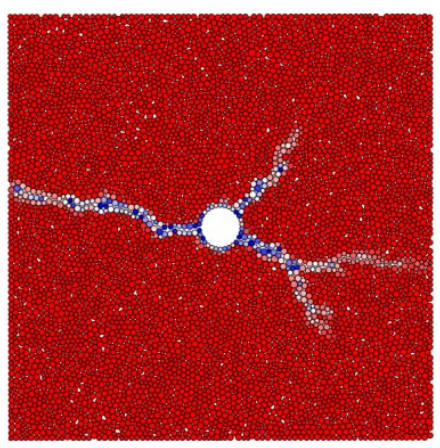

$\sigma_{3}=30 \mathrm{MPa}, \mathrm{T}=600{ }^{\circ} \mathrm{C}$
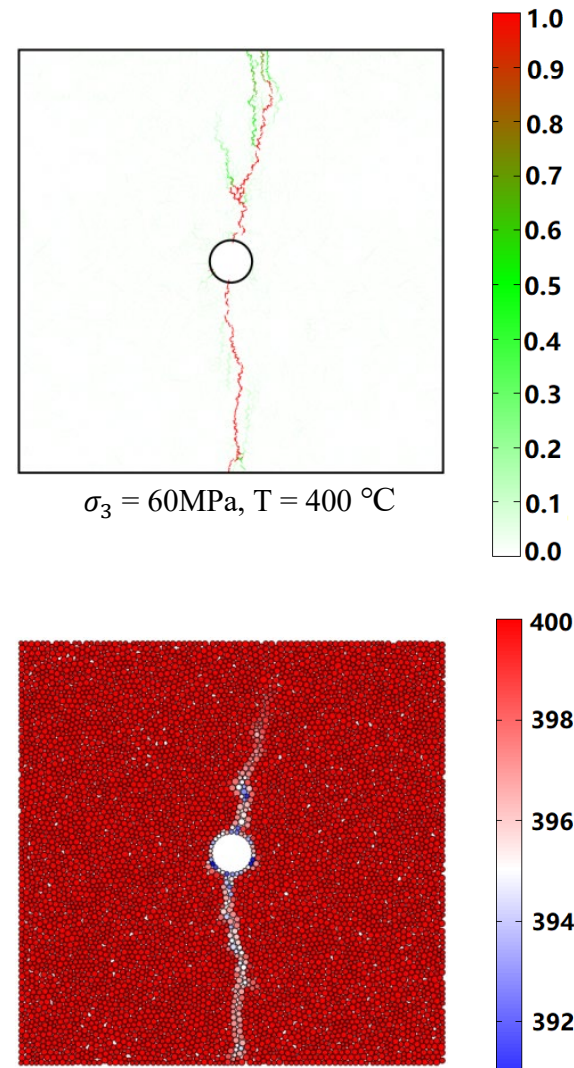

$\sigma_{3}=60 \mathrm{MPa}, \mathrm{T}=400^{\circ} \mathrm{C}$

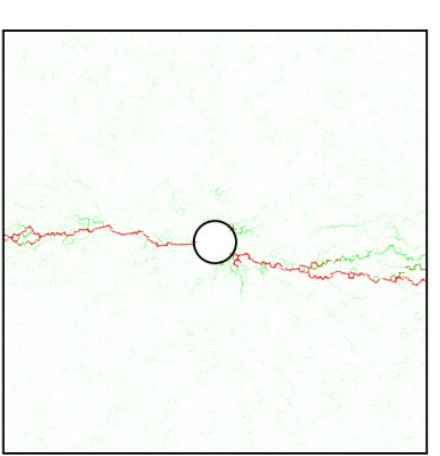

$\sigma_{3}=60 \mathrm{MPa}, \mathrm{T}=600^{\circ} \mathrm{C}$

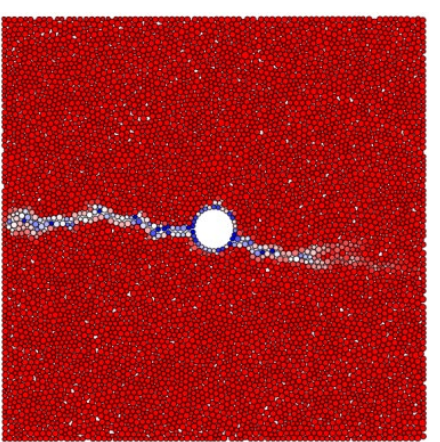

$\sigma_{3}=60 \mathrm{MPa}, \mathrm{T}=600^{\circ} \mathrm{C}$

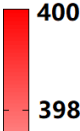

396

394

392

390
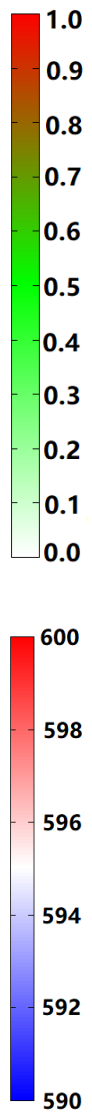

Fig. 11. The crack patterns and corresponding temperature distribution $\left({ }^{\circ} \mathrm{C}\right)$ when the injection fluid viscosity is $100.0 \mathrm{mPa} . \mathrm{s}$ at $400^{\circ} \mathrm{C}$ and $600^{\circ} \mathrm{C}$. 
From Fig. 11, compared with the room temperature, when the temperature is $400^{\circ} \mathrm{C}$, there is no apparent change in the distribution characteristics of hydraulic cracks. Besides, the temperature reduction of grains around hydraulic cracks lags behind the propagation of the cracks when high-viscosity fluid is used because high-viscosity fluids have low flowability.

When the temperature is raised to $600^{\circ} \mathrm{C}$, compared with $400^{\circ} \mathrm{C}$, more hydraulic fractures could be observed under the confining pressure of 5MPa. As the confining pressure increases, the development of hydraulic cracks is suppressed, and the number of hydraulic cracks decreases.

At different temperature, the relationship between the average crack width and the confining pressure when the borehole pressure reaches stabilized pressure is summarized in Table 6:

Table 6 Average crack width under different confining pressure and temperature.

\begin{tabular}{|c|c|c|c|}
\hline Confining pressure/MPa & 5 & 30 & 60 \\
\hline 25 & 0.0000087 & 0.0000041 & 0.0000052 \\
\hline 400 & 0.0000074 & 0.0000059 & 0.0000029 \\
\hline 600 & 0.000019 & 0.000011 & 0.0000048 \\
\hline
\end{tabular}

As the confining pressure increases, the average crack width tends to decrease. Compared to using lowviscosity fluid, the difference in average crack width at $25^{\circ} \mathrm{C}$ and $400^{\circ} \mathrm{C}$ is reduced, which is caused by more hydraulic cracks induced by high-viscosity fluid. The average crack width at $600^{\circ} \mathrm{C}$ is still the largest and is greater than the crack width when using low-viscosity fluid under the same conditions.

\section{Discussions}

For EGS used for power generation and the factors mentioned above, different heating rates caused by different geothermal gradients are also significant factors that affect the mechanical properties of rock mass, which is worth discussing-considering that the magnitude of loading rate and strain rate in the DEM algorithm is quite different from the actual test. Here we aim to qualitatively discuss the influence of different heating rates on the mechanical properties of the rock, rather than calibrating the precise thermodynamic response of a particular rock.

In the process of numerical simulation, the numerical model is first heated to the target temperature at different rates $\left(0.45^{\circ} \mathrm{C} / \mathrm{min}, 0.9^{\circ} \mathrm{C} / \mathrm{min}, 1.35^{\circ} \mathrm{C} / \mathrm{min}\right)$ and then cooled to room temperature at the same rate after the model reaches a stable state. The mechanical parameters of the model are shown in Table 1. After this thermal 
treatment process, the model is used for the uniaxial compression test. The numerical results of stress-strain curves are shown in Fig. 12:

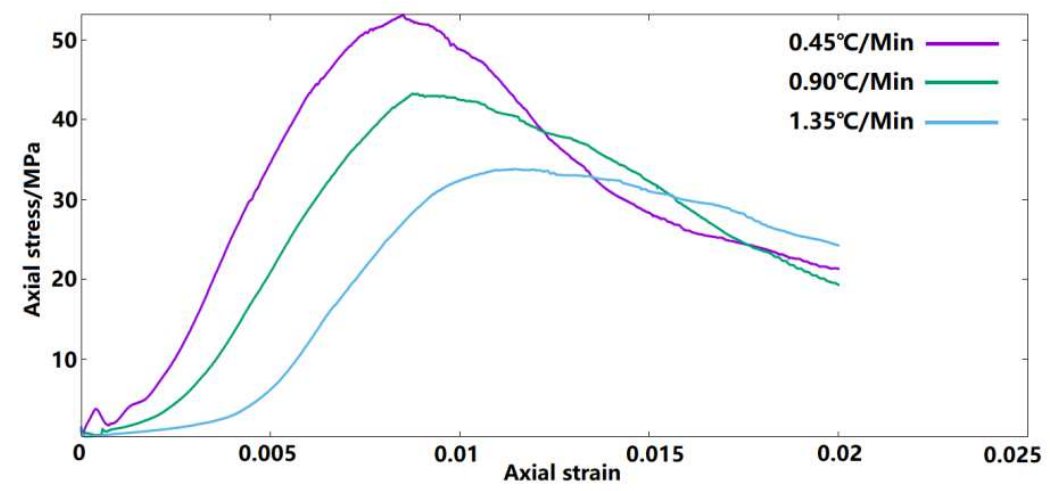

(a) Thermal treatment temperature: $800^{\circ} \mathrm{C}$

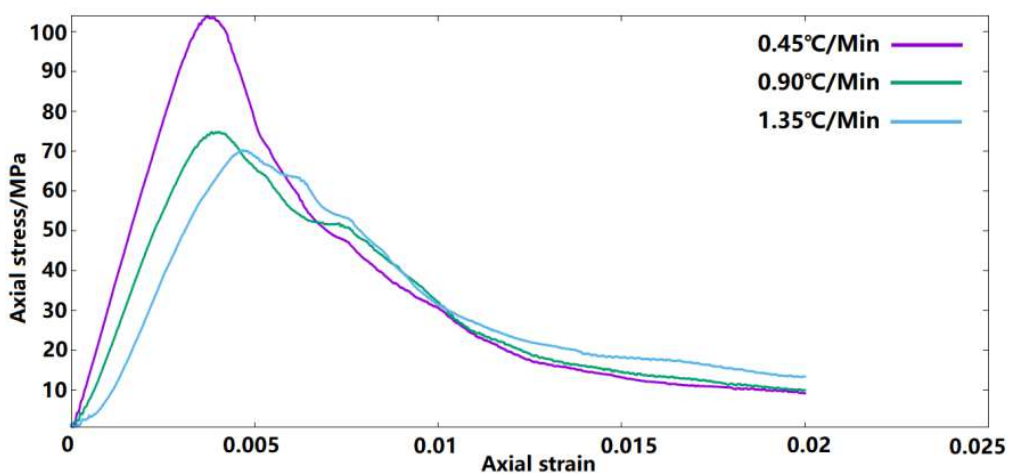

(b) Thermal treatment temperature: $600^{\circ} \mathrm{C}$

Fig. 12. The stress-strain curves after treatments at different heating rates and temperatures

From Fig. 12, with the increasing heating rate, the dynamic compressive strength, and dynamic elastic modulus decrease, whereas the peak strain increases gradually. This trend is consistent with the experimental results (Shu et al., 2019). Thus, it could also be expected that the rock formation is more likely to be induced to fracture by the injection fluid under a high heating rate. Although the heating rate is an important influencing factor, due to the complicated heating mechanism and stress history of thermal storage rock formation, it could be challenging to determine the corresponding heating rate in actual projects.

Research on the development of geothermal resources has attracted the interest of scholars for a long time. As mentioned before, many experiments on the thermodynamic response of rocks are carried out (Shu et al., 2019; Yang et al., 2017; Rossi et al., 2018, for example), which mainly distinguished from conventional mechanical experiments of rock due to the thermal treatment of specimen. In the thermal treatment stage, specimens are heated to their target temperature through a high-temperature furnace. They are then cooled naturally to room temperature $\left(25^{\circ} \mathrm{C}\right)$ in a confined space. After the thermal treatment, a loading test (mainly the uniaxial compression test) will be conducted to analyze the thermodynamic response of the thermally treated rock specimen. Some theoretical 
research applied the effects of temperature on rock mechanical properties obtained from this type of experiment in numerical simulations (Ohtani et al., 2019a, 2019b, 2019c, for example). It is worth mentioning that because the high-temperature geothermal reservoir rock formation does not have a cooling stage like the processing of laboratory specimens before they are developed, we separate the heating and cooling stages of the numerical model so that our simulation is closer to the actual situation. In the theoretical validation, the thermal treatment of the numerical model includes heating and cooling to keep it consistent with laboratory experiments; only the heating part is retained during the numerical simulation of hydraulic fracturing in order to be consistent with the state of the geothermal reservoir rock formation. Since thermal stress and thermal stress cracks are also generated during the cooling stage, it can be expected that our numerical model will have less initial damage than the model that does not distinguish between heating and cooling stages.

A more significant temperature difference between reservoir rock and injection fluid helps to induce more cracks and theoretically proves the feasibility of using cryogenic liquid (such as liquid nitrogen and Supercritical carbon dioxide) instead of water for fracturing. Waterless fracturing technology has become an alternative to traditional hydraulic methods in recent years (Huang et al., 2020). In particular, these technologies are usually closely related to supercritical fluids. Take liquid nitrogen $\left(\mathrm{LN}_{2}\right)$ as an example, the critical pressure and critical temperature of $\mathrm{LN}_{2}$ are $3.4 \mathrm{MPa}$ and $-147^{\circ} \mathrm{C}$, respectively. During field application of $\mathrm{LN}_{2}$ fracturing, the injection pressure will exceed the critical pressure in most cases, and the injected $\mathrm{LN}_{2}$ will translate into a supercritical state after being heated up. In the supercritical state, distinct liquid and gas phases do not exist. The properties of the fluid will change significantly with temperature and pressure. Since the complex heat transfer phenomena involved in the supercritical state are still unclear, corresponding theoretical research is of great importance, which is one of our future research directions.

\section{Conclusions}

In the present study, we developed a new scheme to incorporate the effect of thermal stress cracks induced by thermal expansion or shrinkage into DEM for simulating the failure behavior of reservoir rocks in EGS. We conduct hydraulic fracturing simulations under various temperatures, confining pressure, and injection fluid conditions. From the numerical results, we notice that high temperature and high-viscosity injection fluid both tend to cause more complicated failure mode, resulting in more and wider hydraulic cracks. As the confining pressure increases, the breakdown pressure and stabilized pressure increase. High-viscosity injection fluid also has a similar effect. The propagation of hydraulic cracks shows a decreasing trend with increasing confining pressure caused by crack closure. In the high temperature cases, the thermal expansion of grains will cause the width of the 
hydraulic cracks to decrease, but the initial thermal stress cracks caused by the thermal expansion of grains help to form more hydraulic cracks. The influence of initial thermal stress cracks gradually dominates with the increase of temperature, and the breakdown pressure and stabilized pressure tend to decrease. The network of the hydraulic cracks is affected by the combined effect between the temperature and the confining pressure. In actual geothermal development, to induce more hydraulic cracks, high-viscosity fluid is a feasible solution. In addition, since the temperature of rock formation is often proportional to the buried depth, high temperature and high pressure usually appear together. This environmental feature means that the confining pressure that increases with the temperature suppresses the propagation of fractures, although the high-temperature rock formation may be conducive to develop hydraulic fractures during the fracturing process. Therefore, a significant temperature difference between reservoir rock and injection fluid is needed to overcome the inhibition of high confining pressure on the development of cracks that forms a complex and extensive network of cracks,.

\section{Data availability statement}

We have confirmed that all the data in this manuscript are available online, and the corresponding data and codes could be obtained by contacting the corresponding author.

\section{References}

1) Al-Busaidi, A., Hazzard, J. F., \& Young, R. P. (2005). Distinct element modeling of hydraulically fractured L ac du Bonnet granite. Journal of Geophysical Research-Solid Earth. 110, B06302. https://doi.org/10.1029/2004J B003297.

2) Anna, S., Mirosława, B., Tomasz, J., 2013. High temperature versus geomechanical parameters of selected rocks-the present state of research. Journal of Sustainable Mining. 12, 45-51. https://doi.org/10.7424/jsm130407.

3) Brady B. H, G., Brown E. T., 1992. Rock mechanics for underground mining, 2nd ed. Chapman \& Hall, London.

4) British Petroleum, 2020. bp Statistical Review of World Energy June 2020. https://www.eqmagpro.com/wpcontent/uploads/2020/06/bp-stats-review-2020-all-data-1_compressed.pdf (accessed on 18 May 2021).

5) Cundall, P. A., Strack, O. D. L., 1979. A discrete numerical model for granular assemblies. Geotechnique. 29 (1), 47-65. https://doi.org/10.1680/geot.1979.29.1.47.

6) Fang, Z., Harrison J. P., 2001. A mechanical degradation index for rock. International Journal of Rock Mechanics and Mining Sciences. 38, 1193-1199. https://doi.org/10.1016/S1365-1609(01)00070-3. 
7) Fang, Z., Harrison, J. P., 2002. Development of a local degradation approach to the modelling of brittle fracture in heterogeneous rocks. International Journal of Rock Mechanics and Mining Sciences. 39, $443-457$. https://doi.org/10.1016/S1365-1609(02)00035-7.

8) Huang, Z., Zhang, S., Yang, R., Wu, X., Li, Ran., Zhang, H., Hung., P., 2020. A review of liquid nitrogen fracturing technology. Fuel, 266, 117040. https://doi.org/10.1016/j.fuel.2020.117040.

9) International Energy Agency, 2020. 2019 IEA Geothermal Annual Report. https://drive.google.com/file/d/1hq z5BB391z_LcaeVERQ_YU5zJbhm-2Ok/view (accessed on 18 May 2021).

10) Ji, P., Zhang, X., Zhang, Q., 2018. A new method to model the non-linear crack closure behavior of rocks under uniaxial compression. International Journal of Rock Mechanics and Mining Sciences. 122, 171-183. https://doi.org/10.1016/j.ijrmms.2018.10.015.

11) Lu, C., Wang, G., 2015. Current status and prospect of hot dry rock research. Science \& Technology Review. 33(19), 13-21. http://www.kjdb.org/CN/10.3981/j.issn.1000-7857.2015.19.001.

12) Lu, S., 2018. A global review of enhanced geothermal system (EGS). Renewable and Sustainable Energy Reviews. 81, 2902-2921. https://doi.org/10.1016/j.rser.2017.06.097.

13) Lund, J. W., Bjelm, L., Bloomquist, G., Mortensen, A.K., 2008. Characteristics, development and utilization of geothermal resources - a Nordic perspective. Episodes. 31, 140-147. https://doi.org/10.18814/epiiugs/2008/v3 1i1/019.

14) Migue, M., Philippe, R., Damian, G., 2009. Hydraulic testing of low-permeability formations: A case study in the granite of Cadalso de los Vidrios, Spain. Engineering Geology. 107, 88-97. https://doi.org/10.1016/j.enggeo.2009.05.010.

15) Montgomery, C., Michael B., 2010. Hydraulic Fracturing: History of an Enduring Technology. Journal of Petroleum Technology, 62, 26-40. https://doi.org/10.2118/1210-0026-JPT.

16) Nagaso, M., Mikada, H., Takekawa, J., 2015. The effects of fluid viscosity on the propagation of hydraulic fractures at the intersection of pre-existing fracture. The 19th International Symposium on Recent Advances in Exploration Geophysics (RAEG 2015). 10.3997/2352-8265.20140188. 
17) Nagaso, M., Mikada, H., Takekawa, J., 2019. The role of rock strength heterogeneities in complex hydraulic fracture formation-Numerical simulation approach for the comparison to the effects of brittleness-. Journal of Petroleum Science and Engineering. 172, 572-587. https://doi.org/10.1016/j.petrol.2018.09.046.

18) Nguyen, N. H. T., Bui, H. H., Nguyen, G. D., Kodikara, J., 2017. A cohesive damage-plasticity model for DEM and its application for numerical investigation of soft rock fracture properties. International Journal of Plasticity, 98, 175-196. https://doi.org/10.1016/j.ijplas.2017.07.008.

19) Ohtani, H., Mikada, H., Takekawa, J., 2019. Simulation of hydraulic fracturing under brittle-ductile transition condition with bond-degradation approaches. 81st EAGE Conference and Exhibition 2019. doi: 10.3997/22144609.201900942.

20) Ohtani, H., Mikada, H., Takekawa, J., 2019. Simulation of ductile failure of granite using DEM with adjusted bond strengths between elements in contact. 81st EAGE Conference and Exhibition 2019. doi: 10.3997/22144609.201900940.

21) Olasolo,P., Juárez, M.C., Morales, M.P., D` Amicoc, S., Liartea, I.A., 2016. Enhanced geothermal systems (EGS): A review. Renewable and Sustainable Energy Reviews. 56, 133-144. https://doi.org/10.1016/j.rser.2015.11.031.

22) Potter, R. M., Robinson, E. S., Smith, M. C., 1974. Patent: Method of extracting heat from dry geothermal reservoirs. The United States, Patent Number 3786858. https://www.osti.gov/biblio/4304847.

23) Pruess, K., 2006. Enhanced geothermal systems (EGS) using CO2 as working fluid-A novel approach for generating renewable energy with simultaneous sequestration of carbon. Geothermics, 35, 351-367. https://doi.org/10.1016/j.geothermics.2006.08.002.

24) Reinsch, T., Dobson, P., Asanuma, H., Huenges, E., Poletto, and F., Sanjuan, B., 2017. Utilizing supercritical geothermal systems: a review of past ventures and ongoing research activities. Geothermal Energy, 5, 1-25. https://doi.org/10.1186/s40517-017-0075-y.

25) Rossi, E., Kant, M. A., Madonna, C., Saar, M. O., Rudolf von Rohr, P., 2018. The Effects of High Heating Rate and High Temperature on the Rock Strength: Feasibility Study of a Thermally Assisted Drilling Method. Rock Mechanics and Rock Engineering, 51, 2957-2964. https://oi.org/10.1007/s00603-018-1507-0. 
26) Shen, Y., Hou, X., Yuan, J., Xu, Z., Hao, J., Gu, L., Liu, Z., 2020. Thermal deterioration of high-temperature granite after cooling shock: multiple-identification and damage mechanism. Bulletin of Engineering Geology and the Environment. 79, 5385-5398. https://doi.org/10.1007/s10064-020-01888-7.

27) Shimizu, H., Murata, S., Ishida, T., 2011. The distinct element analysis for hydraulic fracturing in hard rock considering fluid viscosity and particle size distribution. International Journal of Rock and Mining Sciences. 48, 712-727. https://doi.org/10.1016/j.ijrmms.2011.04.013.

28) Shu, R., Yin, T., Li, X., 2019. Effect of heating rate on the dynamic compressive prop-erties of granite. Geofluids. 8292065. http://dx.doi.org/10.1155/2019/8292065,1-12.

29) Tarasovs, S., Ghassemi, A., 2012. Radial Cracking of a Borehole By Pressure And Thermal Shock. Paper presented at the 46th U.S. Rock Mechanics/Geomechanics Symposium, Chicago, Illinois, 24-27.

30) Tester, J.W., Anderson, B.J., Batchelor, A.S., Blackwell, D.D., DiPippo, R., Drake, E.M., Garnish, J., Livesay, B., Moore, M.C., Nichols, K., Petty, S., Toksöz, M.N., Veatch, Jr., R.W., 2006. The Future of Geothermal Energy - Impact of Enhanced Geothermal Systems (EGS) on the United States in the 21 st Century. Massachusetts Institute of Technology.

31) Tomac, I., Gutierrez, M., 2017. Coupled hydro-thermo-mechanical modeling of hydraulic fracturing in quasibrittle rocks using BPM-DEM. Journal of Rock Mechanics and Geotechnical Engineering. 9 (1), 92-104. https://doi.org/10.1016/j.jrmge.2016.10.001.

32) Van der Meer, F., Hecker, C., Van Ruitenbeek, F., Van der Werff, H., De Wijkerslooth, C., Wechsler, C., 2014. Geologic remote sensing geothermal exploration: a review. International Journal of Applied Earth Observation and Geoinformation. 33, 255-269. https://doi.org/10.1016/j.jag.2014.05.00721.

33) Vazifeshenas, Y., Sajadi, H., 2010. Enhancing residential building operation through its envelope. Energy Systems Laboratory; Texas A\&M University. 26-28. https : //hdl .handle .net /1969 .1/94121.

34) Watanabe, N., Egawa, M., Sakaguchi, K., Ishibashi, T., Tsuchiya, N., 2017. Hydraulic fracturing and permeability enhancement in granite from subcritical/brittle to supercritical/ductile conditions. Geophysical Research Letters, 44, 5468-5475. https://doi.org/10.1002/2017GL073898.

35) Wong, L. N. Y., Zhang, Y., Wu, Z., 2020. Rock strengthening or weakening upon heating in the mild temperature range?. Engineering Geology, 272, 105619. https://doi.org/10.1016/j.enggeo.2020.105619. 
36) Yang, S., Ranjith, P., Jing, H., Tian, W., Ju, Y., 2008. A discrete element model for the development of compaction localization in granular rock. Journal of geophysical research, 113, B03202. https://doi.org/10.1029/2006JB004501.

37) Yang, S., Ranjith, P., Jing, H., Tian, W., Ju, Y., 2017. An experimental investigation on thermal damage and failure mechanical behavior of granite after exposure to different high temperature treatments. Geothermics, 65 , 180-197. https://doi.org/10.1016/j.geothermics.2016.09.008.

38) Zhang, F., Zhao, J., Hu, D., Skoczylas, F., Shao, J., 2018. Laboratory Investigation on Physical and Mechani cal Properties of Granite After Heating and Water-Cooling Treatment. Rock Mechanics and Rock Engineering. 5 1, 677-694. https://doi.org/10.1007/s00603-017-1350-8. 
Figures

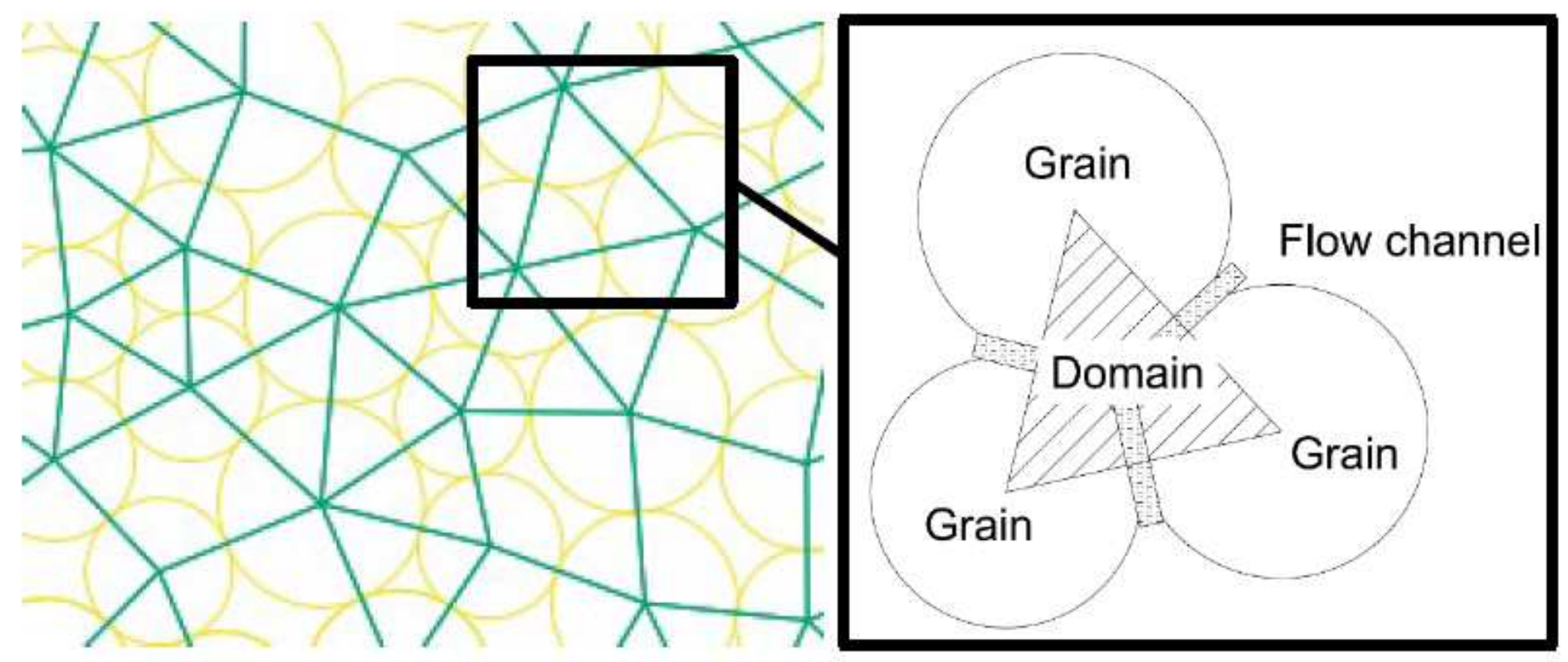

Figure 1

Channel-domain model, domains are represented as the area enclosed by solid green lines. Yellow circles represent grains. 


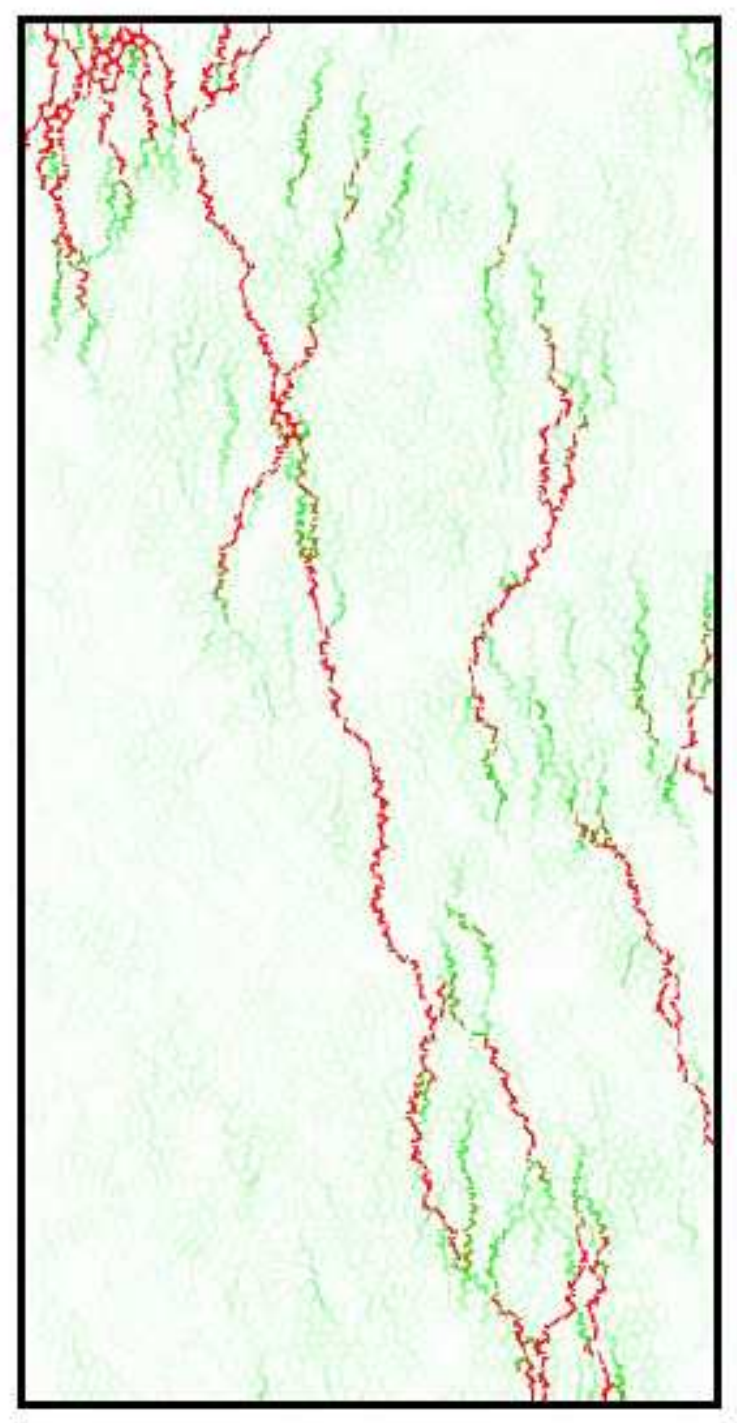

(a)

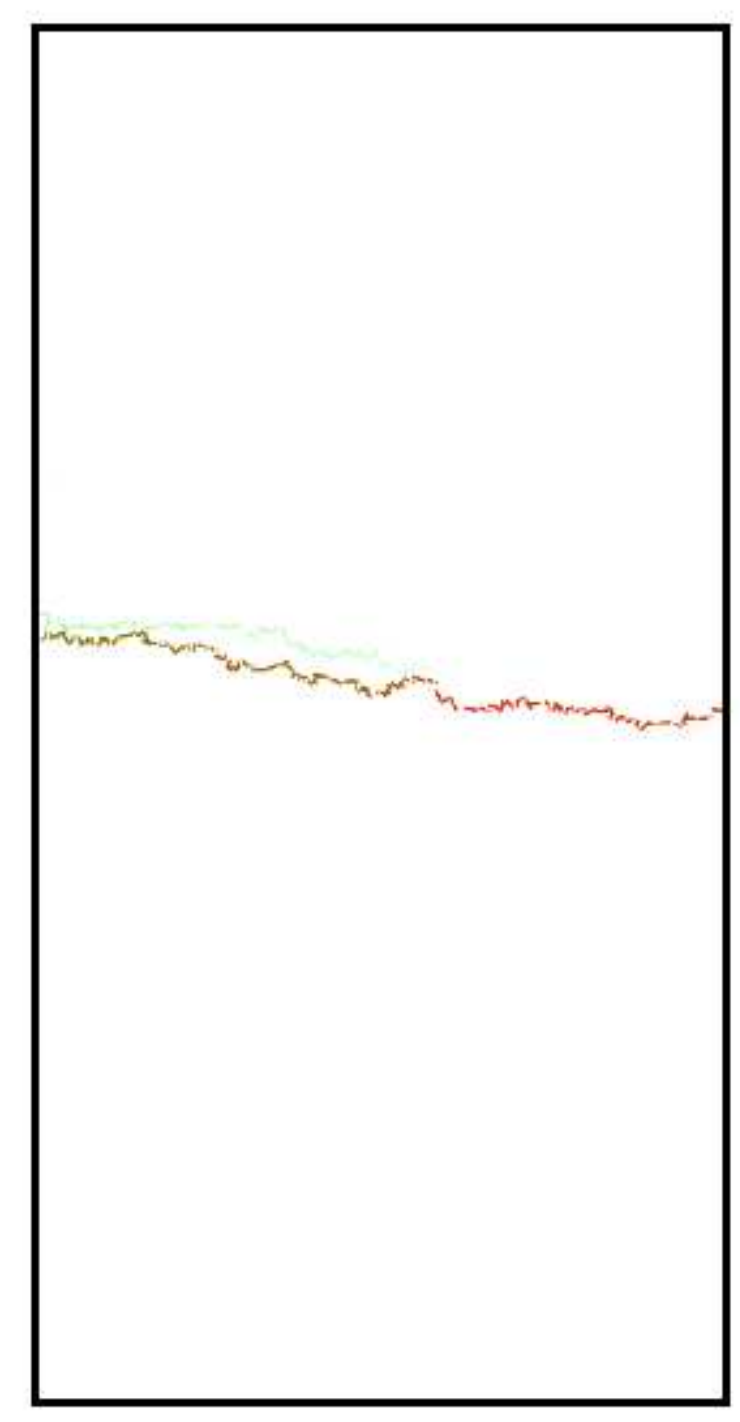

(a)

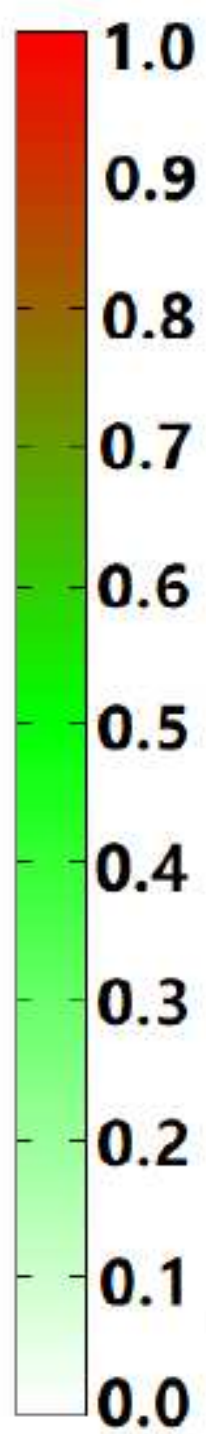

Figure 2

Crack distribution patterns of uniaxial compression test (a) and direct tension test (b). 


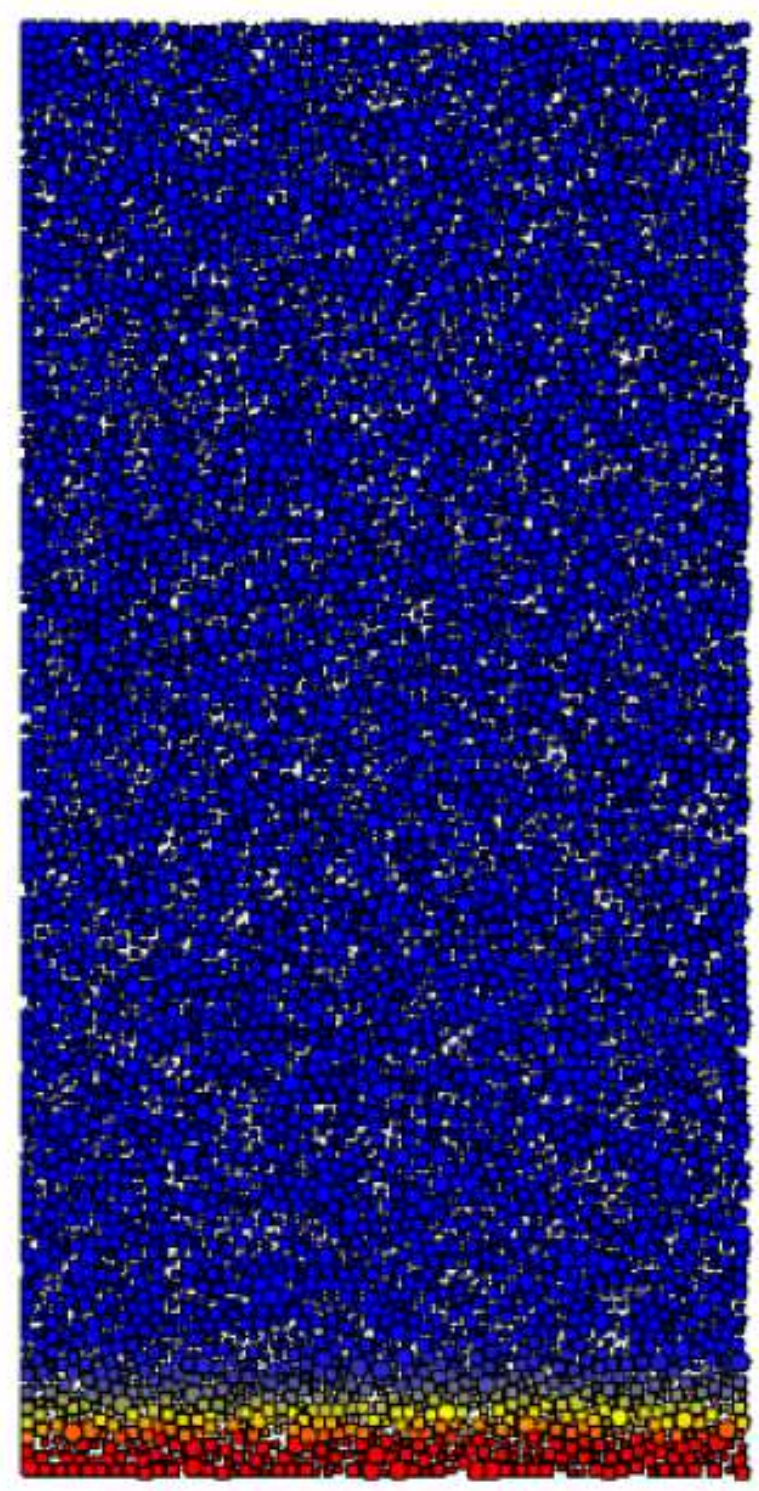

(a) Initial state

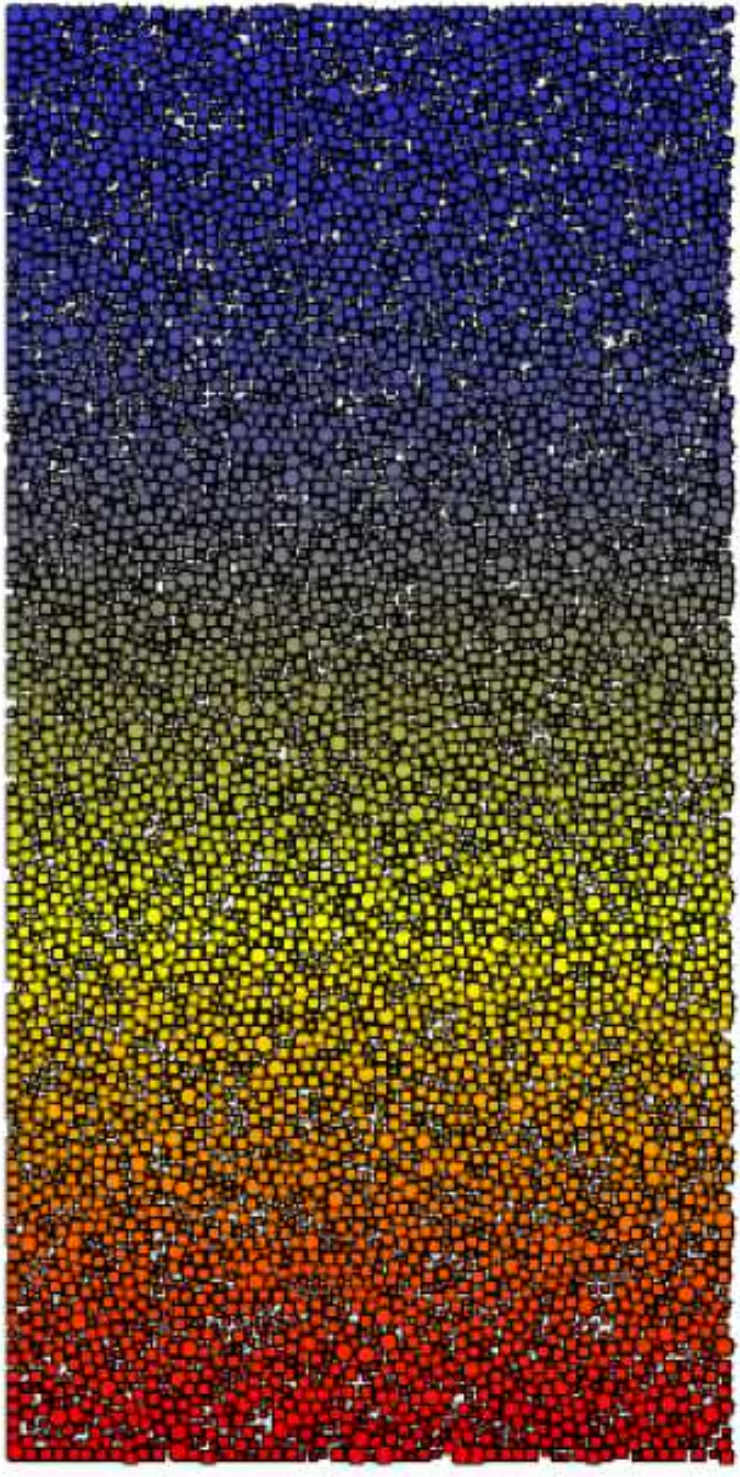

100

80

60

40

20

(a) After 300,000 iterations

Figure 3

Changes in the temperature distribution of the numerical model. Color scale represents the temperature of grains. 


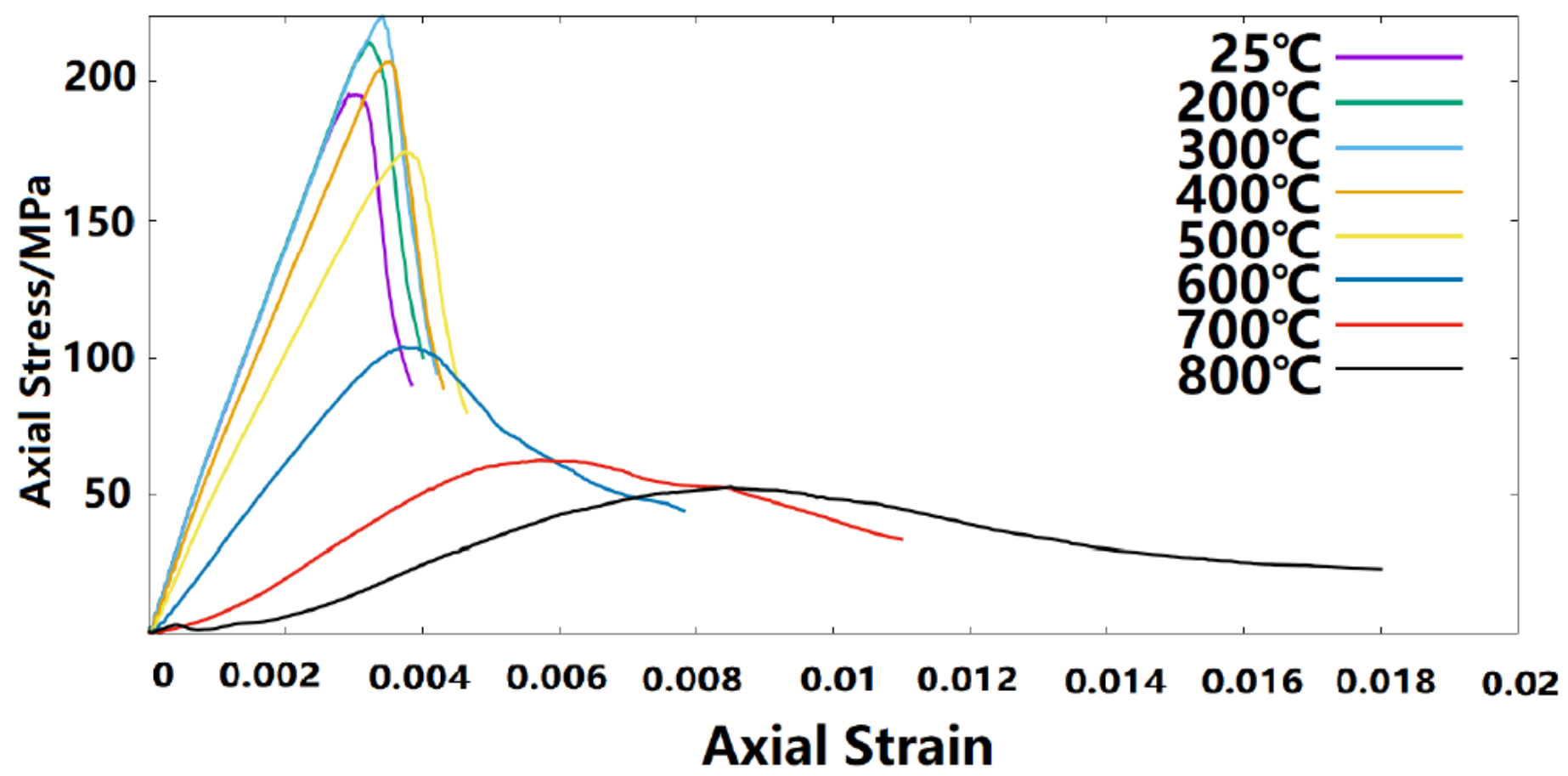

Figure 4

Axial stress-strain curves of uniaxial compression tests under different temperatures $(\mathbb{\nabla})$ obtained by numerical simulation.

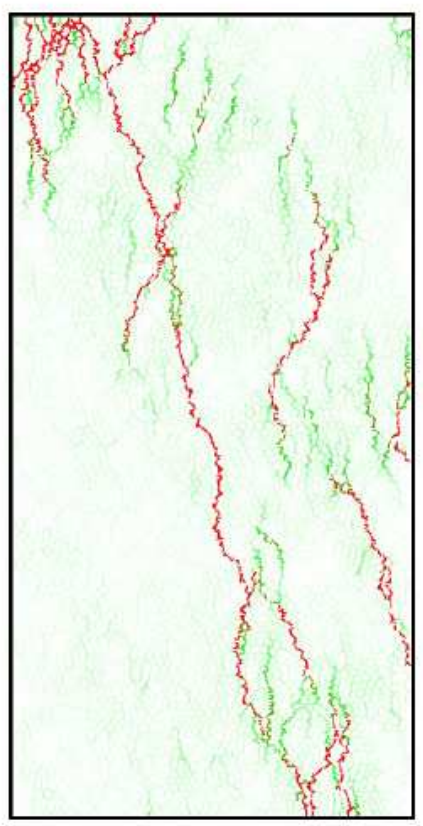

(a)

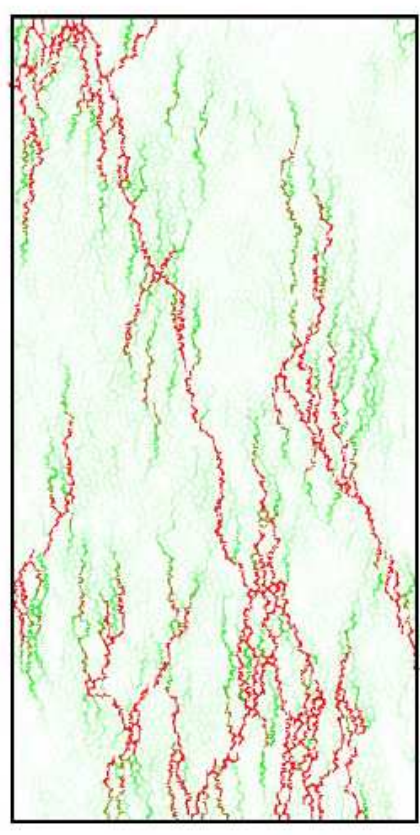

(b)

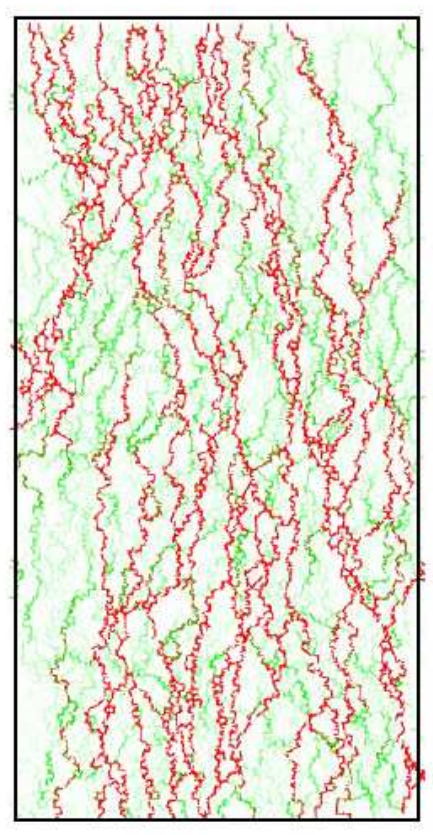

(c)

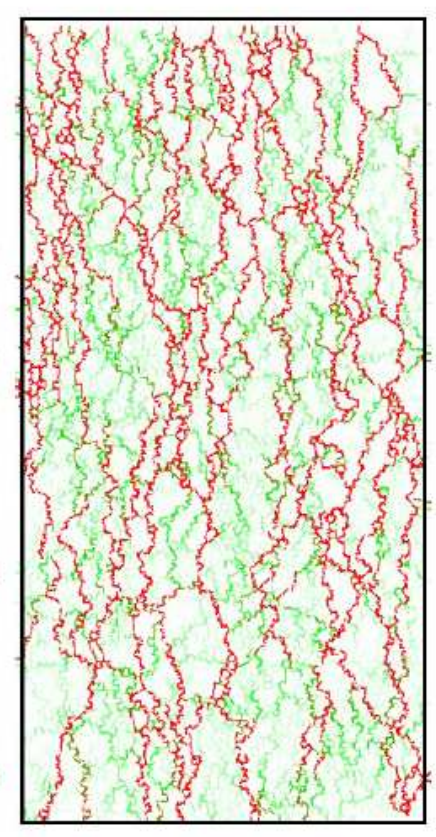

1.0

0.9

0.8

0.7

0.6

0.5

0.4

0.3

0.2

0.1

0.0

\section{Figure 5}

Numerical model at $25 \otimes(a), 300 \otimes(b), 700 \otimes(c)$ and $800 \otimes(d)$ after uniaxial compression failure 


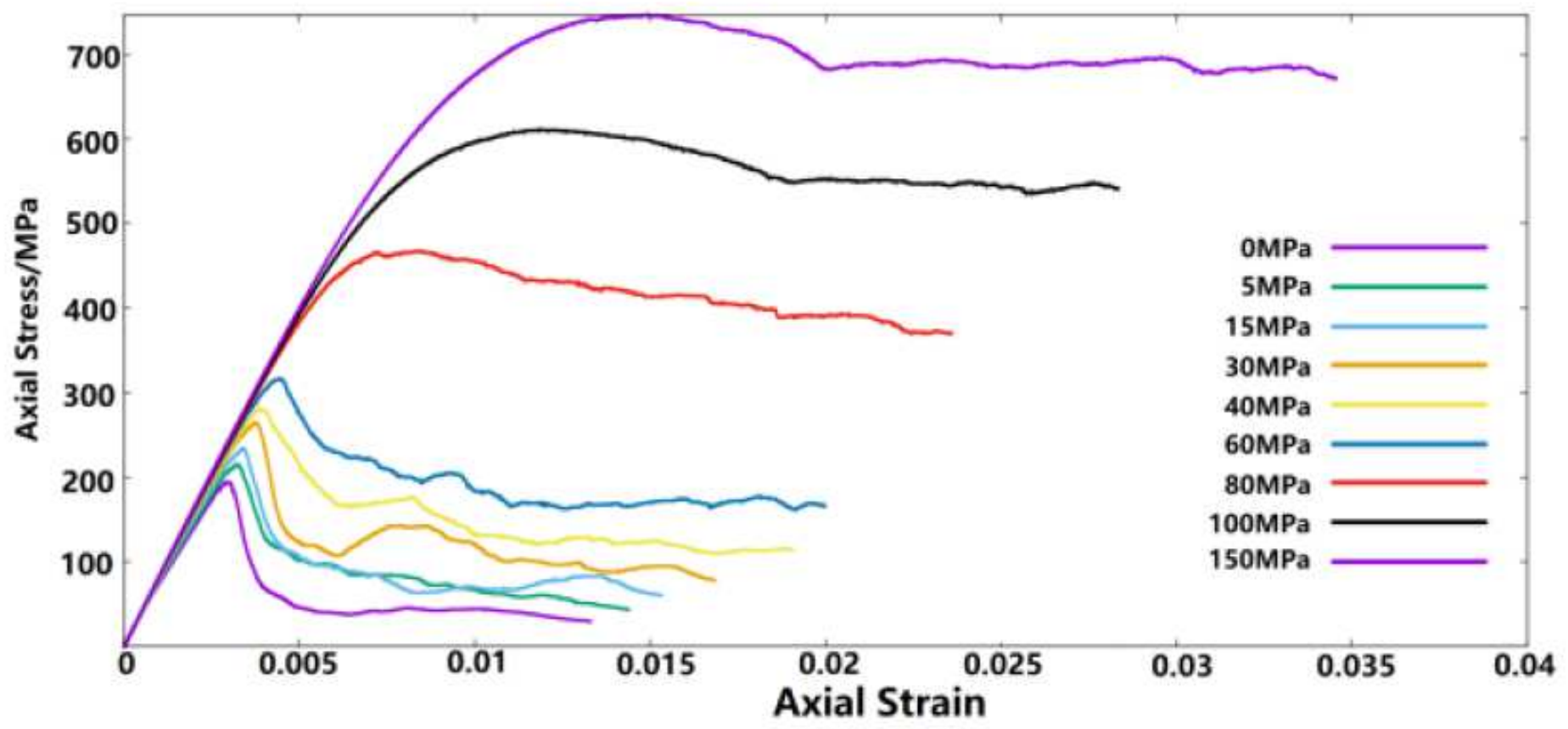

Figure 6

Axial Stress-strain curves with different confining pressure. The vertical and horizontal axes are the axial stress and axial strain, respectively. 


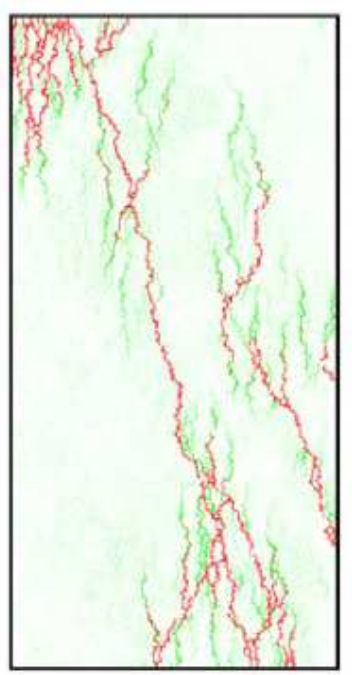

(a) Unconfined

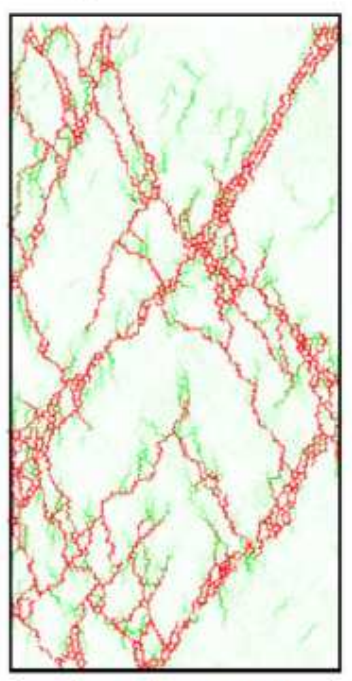

(f) $\sigma_{3}=60 \mathrm{MPa}$

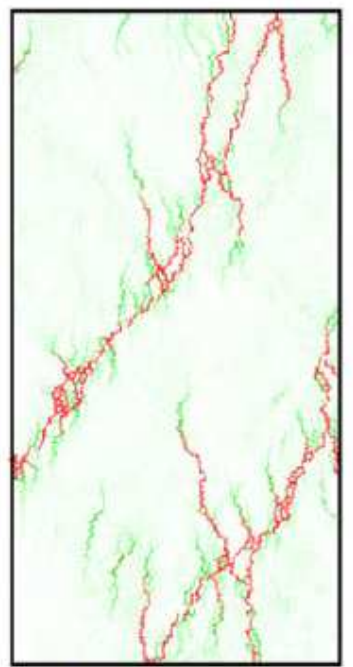

(b) $\sigma_{3}=5 \mathrm{MPa}$

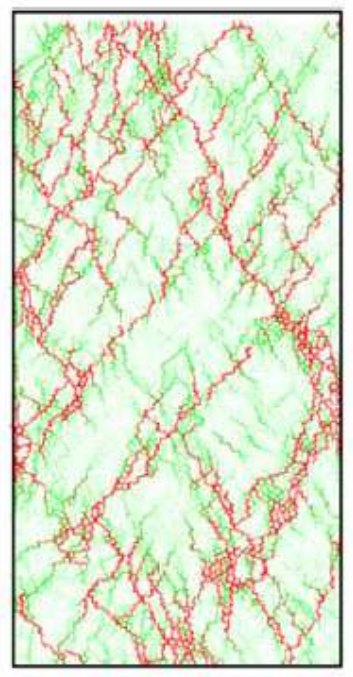

(g) $\sigma_{3}=80 \mathrm{MPa}$

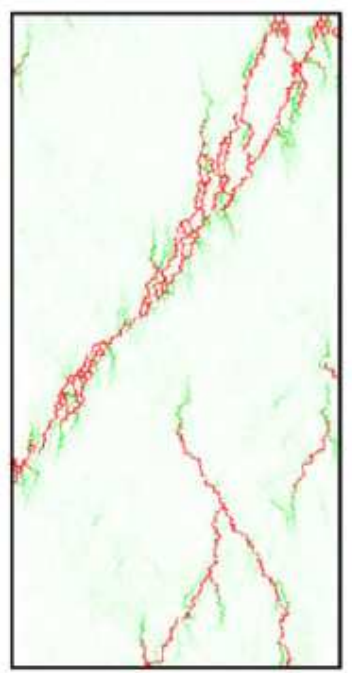

(c) $\sigma_{3}=15 \mathrm{MPa}$

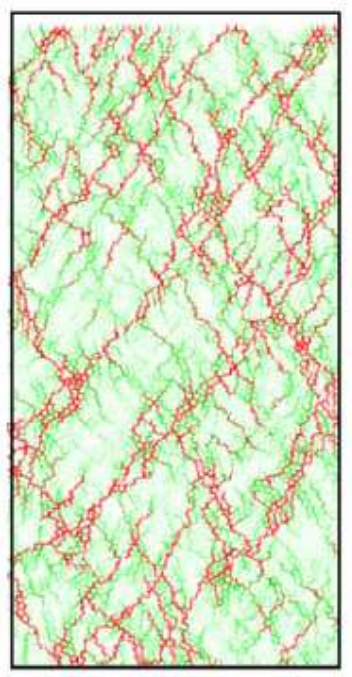

(h) $\sigma_{3}=100 \mathrm{MPa}$

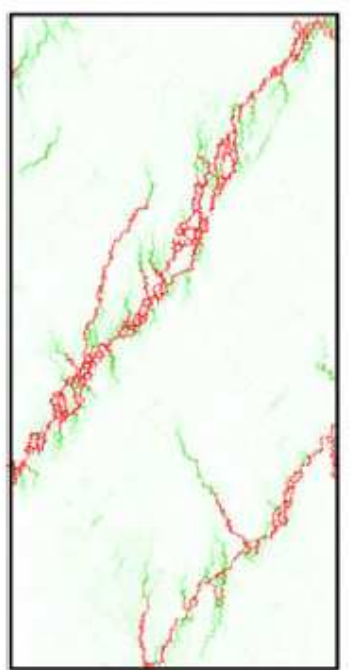

(d) $\sigma_{3}=30 \mathrm{MPa}$

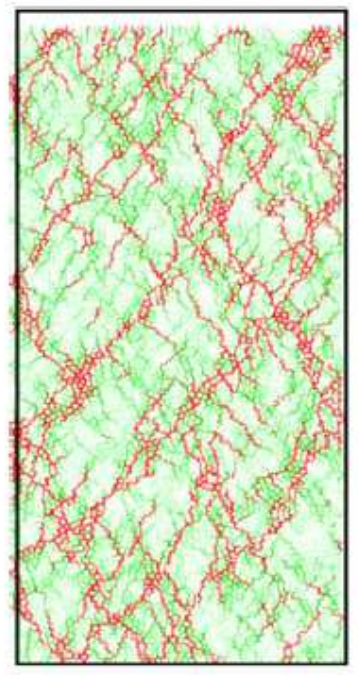

(h) $\sigma_{3}=150 \mathrm{MPa}$

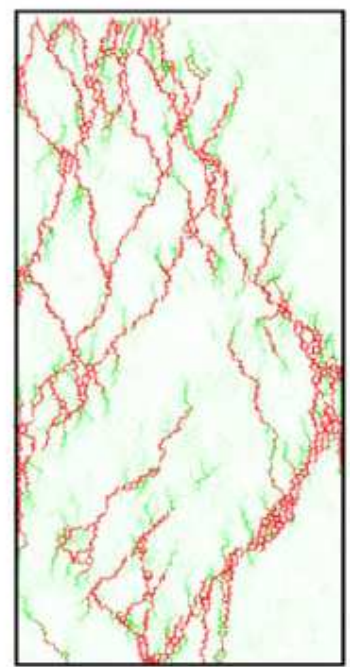

(e) $\sigma_{3}=40 \mathrm{MPa}$

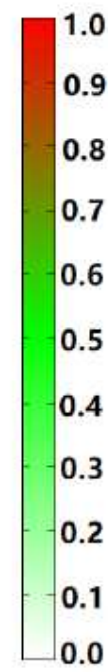

Figure 7

Crack patterns in the numerical specimens of biaxial compression tests under different confining pressure 

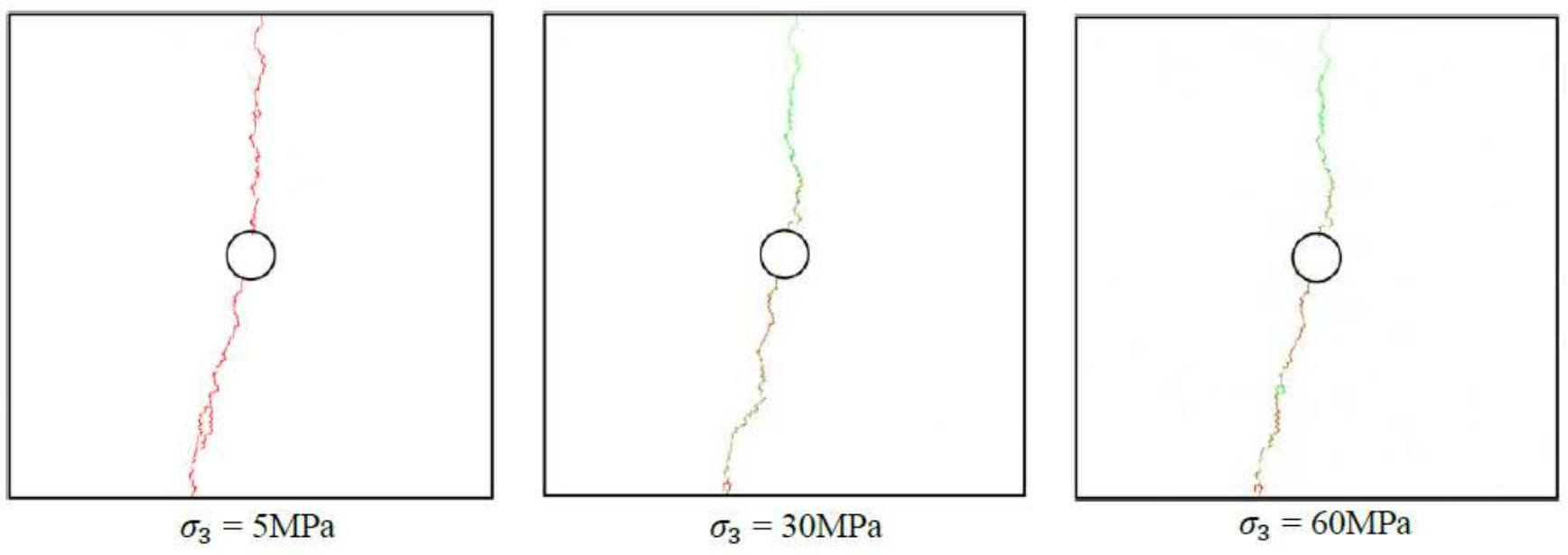

1.0
0.9
0.8
0.7
0.6
-0.5
-0.4
-0.3
-0.2
-0.1
0.0

Figure 8

Crack patterns when the injection fluid viscosity is $0.1 \mathrm{mPa}$.s at room temperature. 


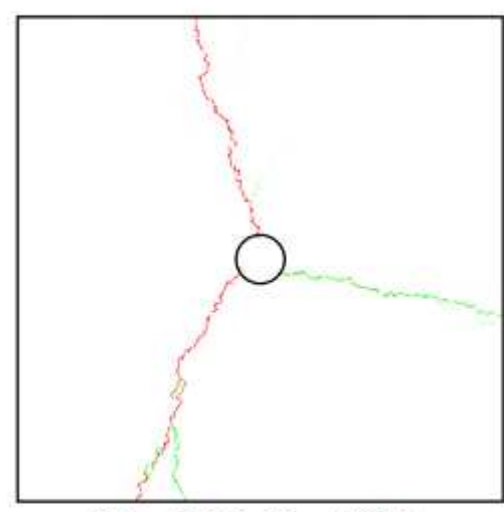

$?_{3}=5 \mathrm{MPa}, \mathrm{T}=400 ?$

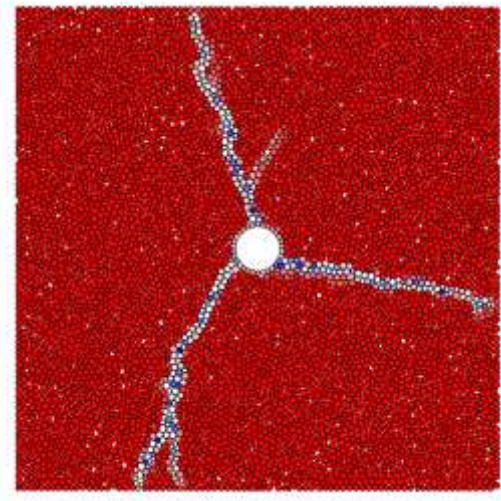

$?_{3}=5 \mathrm{MPa}, \mathrm{T}=400 ?$

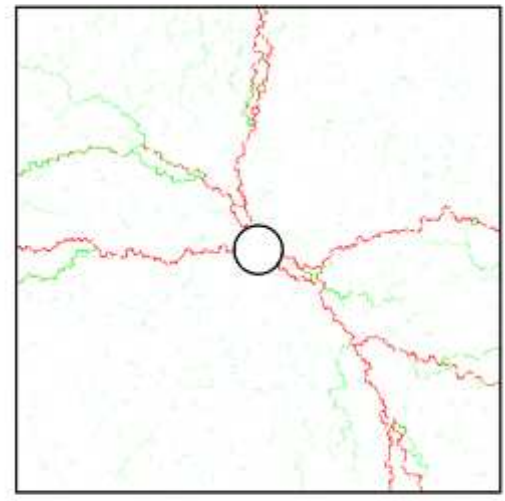

$?_{3}=5 \mathrm{MPa}, \mathrm{T}=600 ?$

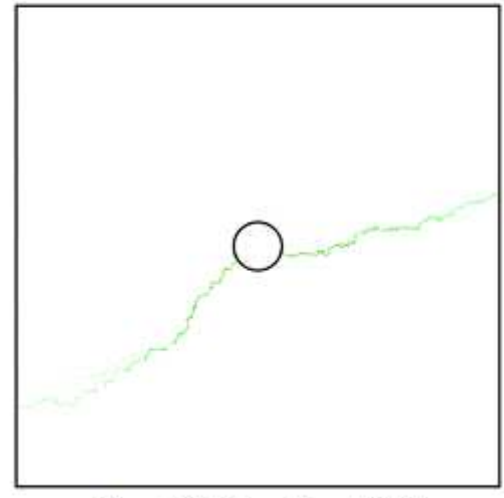

$?_{3}=30 \mathrm{MPa}, \mathrm{T}=400 ?$

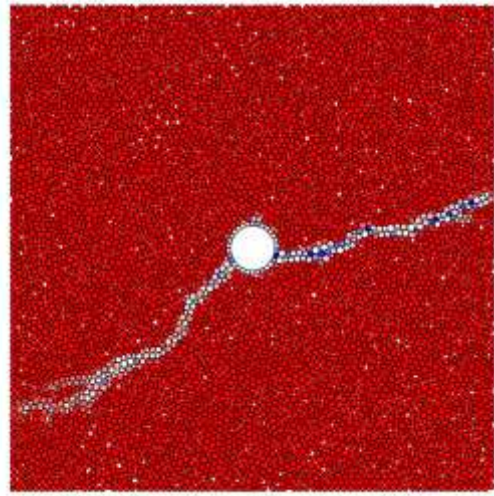

$?_{3}=30 \mathrm{MPa}, \mathrm{T}=400 ?$

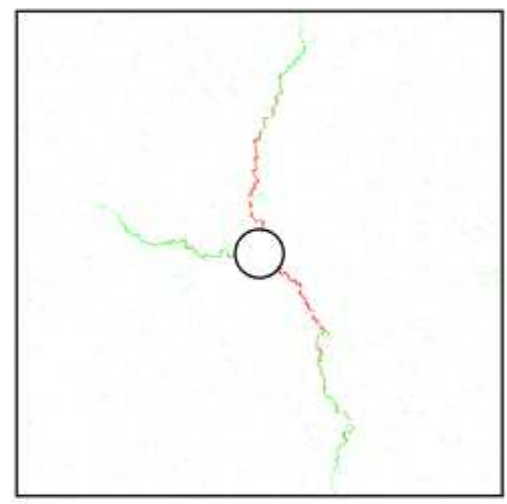

$?_{3}=30 \mathrm{MPa}, \mathrm{T}=600 ?$

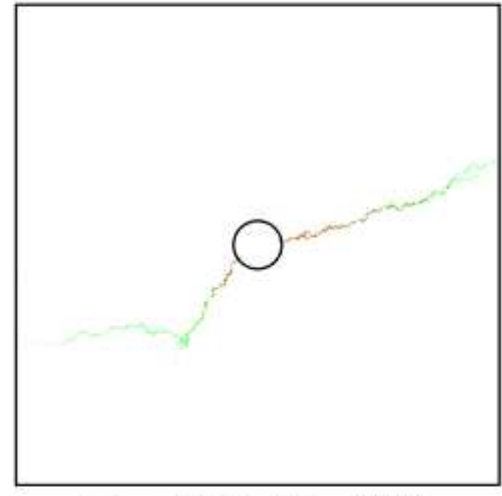

$?_{3}=60 \mathrm{MPa}, \mathrm{T}=400 ?$

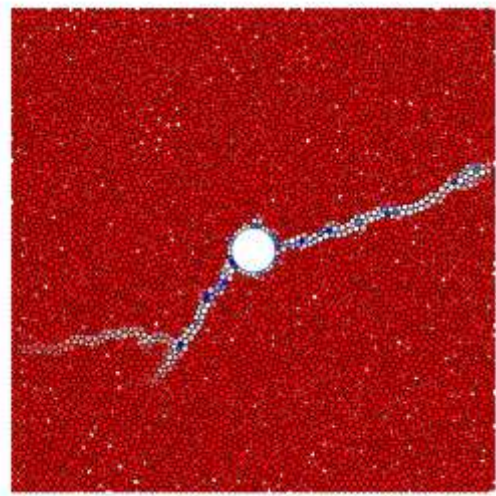

$?_{3}=60 \mathrm{MPa}, \mathrm{T}=400 ?$

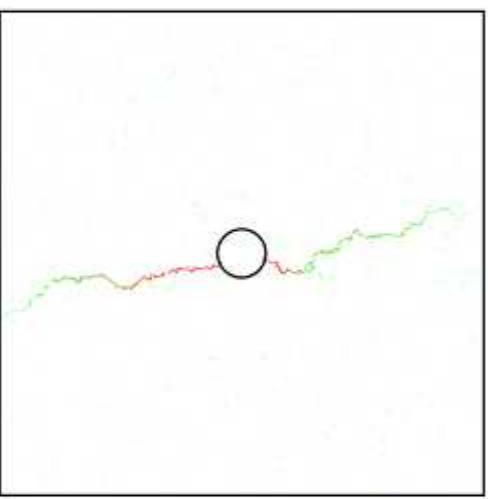

$?_{3}=60 \mathrm{MPa}, \mathrm{T}=600 ?$

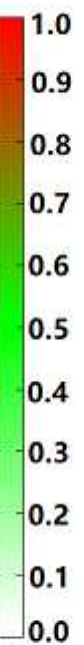

400

398

$-396$

$-394$

392

390

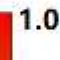

0.9

0.8

0.7

0.6

0.5

0.4

0.3

0.2

0.1

\section{Figure 9}

The crack patterns and corresponding temperature distribution $(\mathbb{})$ when the injection fluid viscosity is 0.1 $\mathrm{mPa}$.s at 400囚 and 600囚. 


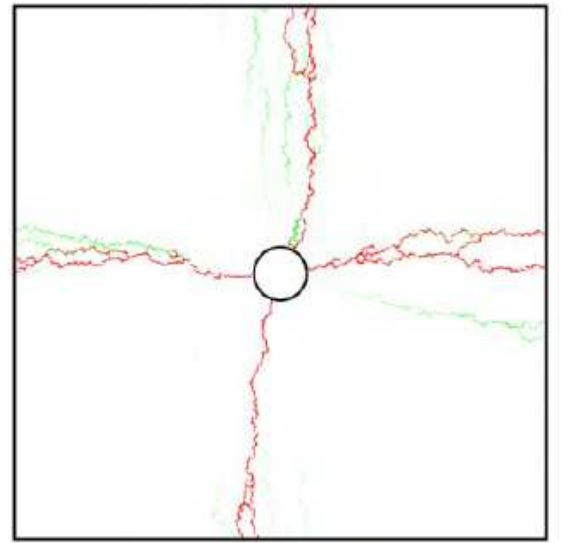

$\sigma_{3}=5 \mathrm{MPa}$

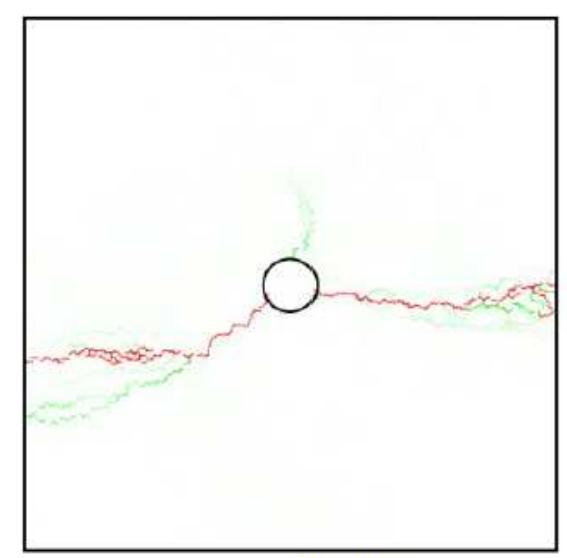

$\sigma_{3}=30 \mathrm{MPa}$

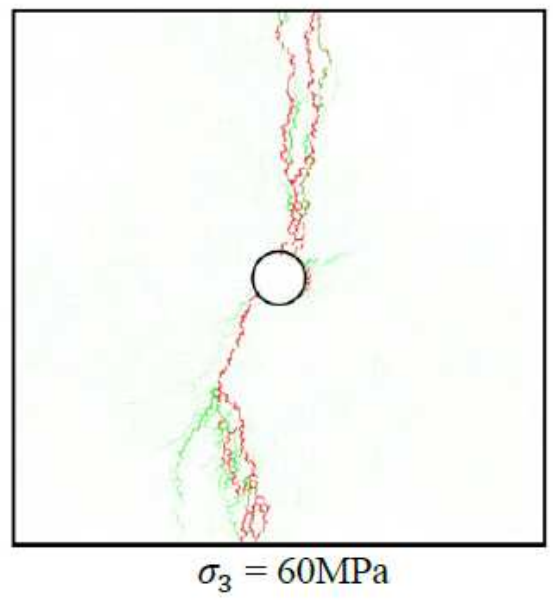
1.0 0.9 0.8 0.7 0.6 0.5 0.4 0.3 $-0.2$ $-0.1$ 0.0

Figure 10

Crack patterns when the injection fluid viscosity is $100 \mathrm{mPa}$.s at room temperature. 


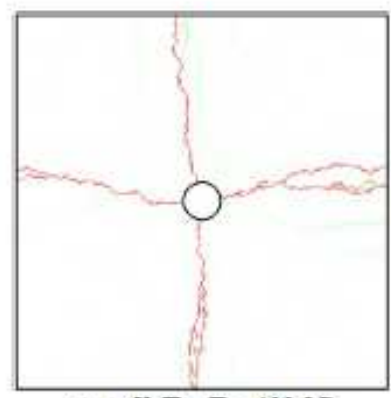

$\sigma_{3}=5 \mathrm{MPa}, \mathrm{T}=400^{\circ} \mathrm{C}$

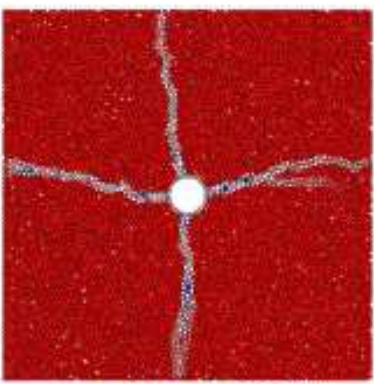

$\sigma_{3}=5 \mathrm{MPa}, \mathrm{T}=400^{\circ} \mathrm{C}$

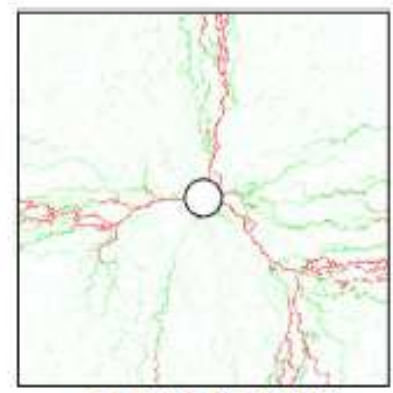

$\sigma_{3}=5 \mathrm{MPa}, \mathrm{T}=600^{\circ} \mathrm{C}$

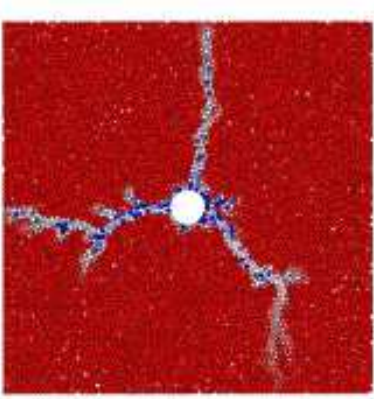

$\sigma_{3}=5 \mathrm{MPa}, \mathrm{T}=600^{\circ} \mathrm{C}$

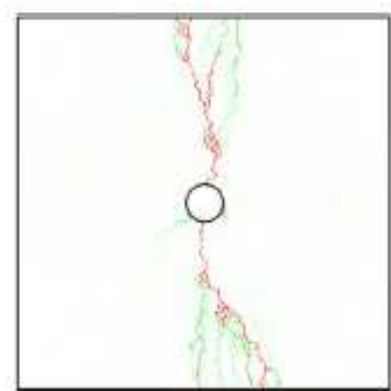

$\sigma_{3}=30 \mathrm{MPa}, \mathrm{T}=400^{\circ} \mathrm{C}$

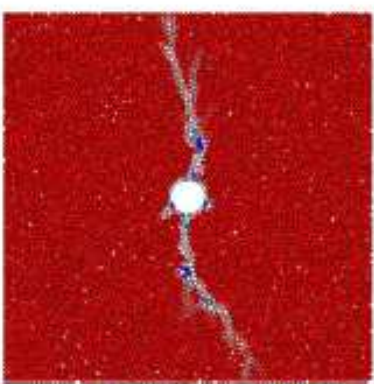

$\sigma_{3}=30 \mathrm{MPa}, \mathrm{T}=400^{\circ} \mathrm{C}$

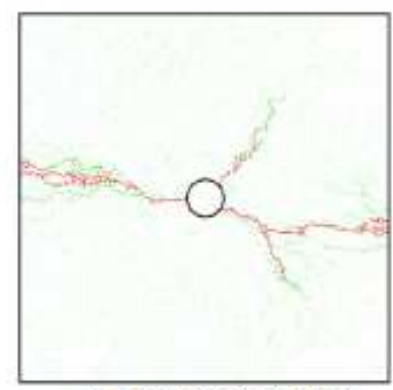

$\sigma_{3}=30 \mathrm{MPa}, \mathrm{T}=600^{\circ} \mathrm{C}$

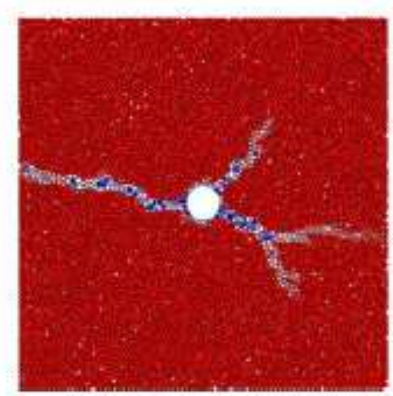

$\sigma_{3}=30 \mathrm{MPa}, \mathrm{T}=600^{\circ} \mathrm{C}$

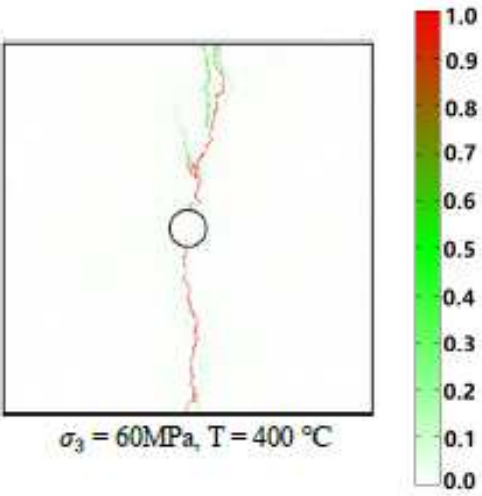

400

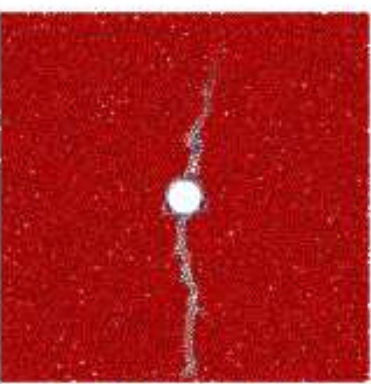

$\sigma_{3}=60 \mathrm{MPa}, \mathrm{T}=400^{\circ} \mathrm{C}$
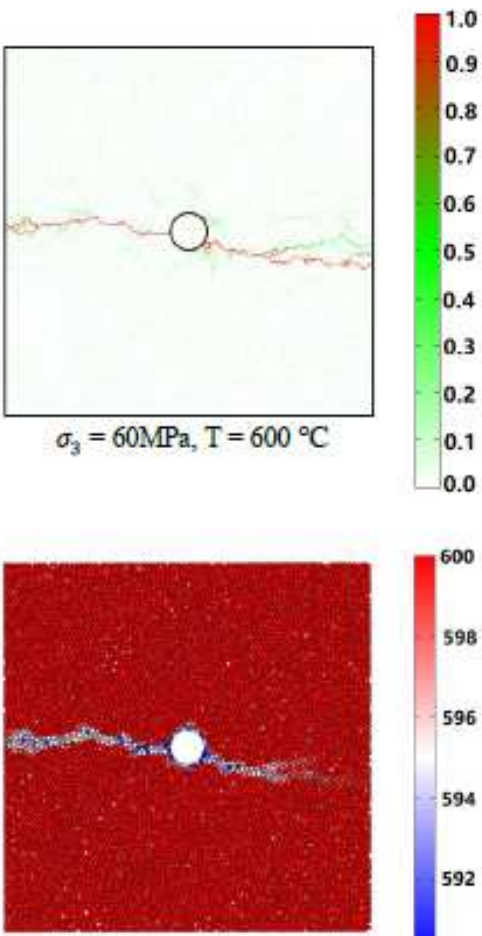

$\sigma_{3}=60 \mathrm{MPa}, \mathrm{T}=600^{\circ} \mathrm{C}$

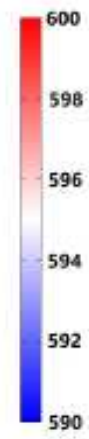

\section{Figure 11}

The crack patterns and corresponding temperature distribution ( $($ ) when the injection fluid viscosity is $100.0 \mathrm{mPa} . \mathrm{s}$ at $400 \mathrm{Q}$ and 600区. 


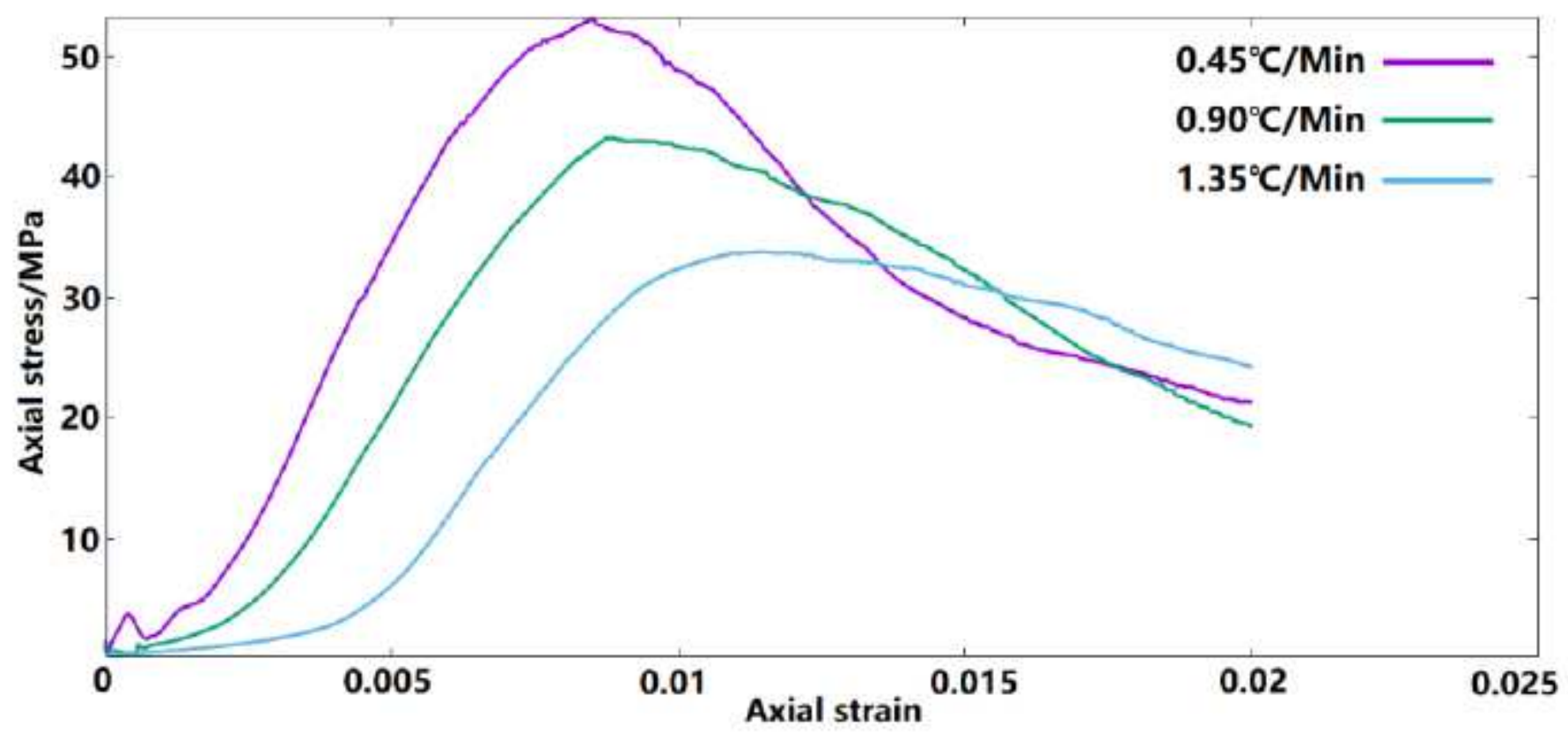

(a) Thermal treatment temperature: $800^{\circ} \mathrm{C}$

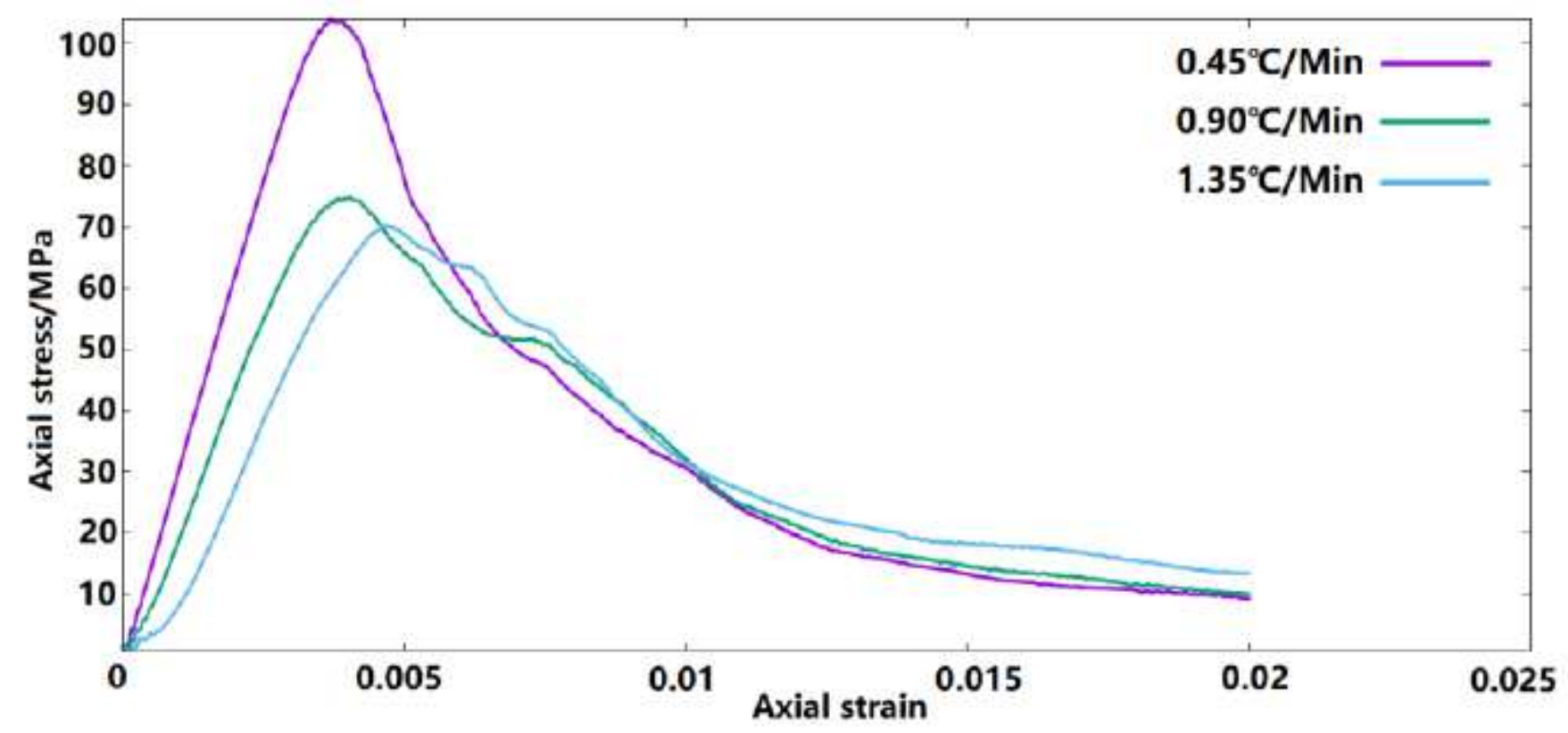

(b) Thermal treatment temperature: $600^{\circ} \mathrm{C}$

Figure 12

The stress-strain curves after treatments at different heating rates and temperatures 